Published in final edited form as:

Prog Retin Eye Res. 2009 January ; 28(1): 1-18. doi:10.1016/j.preteyeres.2008.10.001.

\title{
Molecular pathology of age-related macular degeneration
}

\author{
Xiaoyan Ding a,b,1, Mrinali Patel ${ }^{a, c, 1}$, and Chi-Chao Chan ${ }^{a,{ }^{*}}$ \\ almmunopathology Section, Laboratory of Immunology, National Eye Institute, 10 Center Drive, \\ 10/10N103, Bethesda, MD 20892-1857, USA \\ bZhongshan Ophthalmic Center, Sun Yat-sen University, Guangzhou 510060, PR China \\ 'Howard Hughes Medical Institute, Chevy Chase, MD, USA
}

\begin{abstract}
Age-related macular degeneration (AMD) is a leading cause of irreversible blindness in the world. Although the etiology and pathogenesis of AMD remain largely unclear, a complex interaction of genetic and environmental factors is thought to exist. AMD pathology is characterized by degeneration involving the retinal photoreceptors, retinal pigment epithelium, and Bruch's membrane, as well as, in some cases, alterations in choroidal capillaries. Recent research on the genetic and molecular underpinnings of AMD brings to light several basic molecular pathways and pathophysiological processes that might mediate AMD risk, progression, and/or response to therapy. This review summarizes, in detail, the molecular pathological findings in both humans and animal models, including genetic variations in $C F H, C X 3 C R 1$, and $A R M S 2 / H t r A 1$, as well as the role of numerous molecules implicated in inflammation, apoptosis, cholesterol trafficking, angiogenesis, and oxidative stress.
\end{abstract}

\section{Keywords}

Age-related macular degeneration; Inflammation; Single nucleotide polymorphism; Genetics; Retinal pigment epithelium; Retinal photoreceptors; Drusen; Vascular endothelial growth factor; Bruch's membrane; Molecular pathology

\section{Introduction}

\subsection{Epidemiology of AMD}

Age-related macular degeneration (AMD) was first described in the medical literature in 1875 as "symmetrical central choroidoretinal disease occurring in senile persons" (Hutchison and Tay, 1875). According to the most recent report on the causes of visual impairment by the World Health Organization in 2002, AMD is among the most common causes of blindness, particularly irreversible blindness, in the world. Among the elderly, AMD is regarded as the leading cause of blindness in the world (Gehrs et al., 2006). Currently, in the United States alone, 1.75 million people are affected by AMD and 7 million people are at risk of developing AMD (Friedman et al., 2004). Considering the significant medical, personal, social, and economic costs of AMD, the need for novel therapeutic and preventative strategies for AMD is pressing. Innovation in AMD pharmacotherapy, in turn, depends largely upon a thorough understanding of the molecular mechanisms underlying AMD pathogenesis.

\footnotetext{
*Corresponding author. Tel.: +1 301496 0417; fax: +1 301402 8664. E-mail address: E-mail: chanc@ nei.nih.gov (C.-C. Chan).

1 These authors are equal contributors.
} 


\subsection{Risk factors for AMD}

AMD is a highly complex disease with demographic, environmental, and genetic risk factors. Among demographic and environmental factors associated with AMD, such as age, gender, race, diet, smoking, education, cardiovascular disease, studies have shown that the most established factors are advanced age, cigarette smoking, diet, and race (Coleman et al., 2008; Jager et al., 2008). The age-associated increase in AMD risk might be mediated by gradual, cumulative damage to the retina from daily oxidative stress. Loss of normal physiological function in the aging retinal pigment epithelial (RPE) cells, a specialized neural cell of neuroectoderm origin that provides metabolic support to photoreceptor cells, may also contribute to the formation of drusen deposits classically seen in AMD retina. Alternatively, age-related mitochondrial DNA damage might also play a role in pathogenesis. Further studies on the impact of aging on the structure and function of the retina are certainly necessary to parse out the key pathological changes that lead to AMD.

The relationship between smoking and AMD has been investigated in numerous cross-sectional studies, cohort studies, and case-control studies (Klein, 2007). The majority of studies have found a statistically significant association between smoking and development of AMD. Possible mechanisms by which smoking mediates increased AMD risk include impairment in the generation of antioxidants (e.g. plasma vitamin $\mathrm{C}$ and carotenoids) induction of hypoxia, generation of reactive oxygen species, and alteration of choroidal blood flow. Smoking also has an effect on the immune system (Tsoumakidou et al., 2008). Based on studies (discussed below) demonstrating an immunological component for $\mathrm{AMD}$, it is possible that part of the risk conferred by smoking funnels through inflammatory pathways. This remains to be demonstrated experimentally.

Both fat intake and obesity have been linked to increased risk of AMD (Mares-Perlman et al., 1995; Seddon et al., 2003), and analyses have revealed protective effects from antioxidants, nuts, fish, and omega-3 polysaccharide unsaturated fatty acids (AREDS, 2001; Cho et al., 2001; Seddon et al., 1994, 2001; Smith et al., 2000). Several convincing studies of the dietary effect on AMD are from randomized controlled clinical trials, e.g., Age-Related Eye Disease Study (AREDS), VEGF (Vascular endothelial growth factor) Inhibition Study in Ocular Neovascularization, Clinical Trial and Minimally Classic/Occult Trial of the Anti-VEGF Antibody Ranibizumab in the Treatment of Neovascular Age-Related Macular Degeneration (MARINA) (AREDS, 2001; Bressler et al., 2003; Gragoudas et al., 2004; Rosenfeld et al., 2006). The AREDS demonstrated the efficacy of zinc-antioxidant supplements for preventing or delaying progression of early AMD to late AMD in patients who are at high risk (Bressler et al., 2003). A recent population-based cohort study in Australia (Tan et al., 2008) demonstrated that high dietary lutein and zeaxanthin intake reduced the risk of long-term incident AMD and that high beta-carotene intake was associated with an increased risk of AMD.

Studies on genetic determinants of AMD have developed slowly because (1) AMD is a disease of old age, surviving parents and well-established family trees are rare; (2) AMD is likely to be a complex disease with numerous etiological factors; (3) the completion of the Human Genome Project with the access to human genome sequence data was only 5 years ago. Instead of having a single contributory gene, a polygenic pattern with multiple genes of variable effect may be involved. Considerable evidence in family, twin and sibling studies exists and suggests a genetic basis of AMD. Several family studies have shown that patients with a family history of AMD are at increased risk (Seddon et al., 2007; Smith and Mitchell, 1998). Recently, Luo et al. identified 4764 AMD patients, analyzed the familial aggregation and estimated the magnitude of familial risks in a population-based cross-sectional and case-control study. The results showed that for AMD, the population-attributable risk (PAR) for a positive family history was 0.34 . Recurrence risks in relatives indicate increased relative risks in siblings 
(2.95), first cousins (1.29), second cousins (1.13), and parents (5.66) of affected cases (Luo et al., 2008). Many linkage and association studies have indicated that the most replicated signals reside on chromosome 1q25-31 and 10q26 (Fisher et al., 2005; Jakobsdottir et al., 2005; Klein et al., 1998; Majewski et al., 2003). We will discuss the genetic factors underlying AMD pathology further in the "single nucleotide polymorphisms" and "molecular pathology of AMD" sections below.

In this article, we review the histopathologic findings that define AMD, along with new molecular pathologic findings that have advanced our understanding of the molecular mechanisms of AMD pathogenesis.

\section{Pathology of AMD}

The progression of AMD occurs over an extended time frame, with the incidence of the disease increasing dramatically over the age of 70. AMD is a multifactorial disease that affects primarily the photoreceptors and RPE, Bruch's membrane, and choriocapillaries. Aging is associated with changes in the retina, including alterations in RPE cellular size and shape, thickening of Bruch's membrane, thickening of the internal limiting membrane, and a decrease in retinal neuronal elements (Green, 1996).

Classically, subretinal, extracellular deposits composed of glycoproteins and lipids accumulate in Bruch's membrane. These dumbbell shaped deposits are called drusen (singular 'druse'). The presence of a few small hard drusen in the peripheral retina is considered a normal part of the aging process. However, the presence of large and many drusen in the macula signifies early AMD. The presence of inflammation-related molecules in drusen suggests the possible involvement of the immune system in AMD pathogenesis (Hageman et al., 2001). A recent study of age-related changes demonstrates recruitment of leukocytes and activation of the complement cascade in mouse RPE and choroid (Chen et al., 2008). These age-related changes may provide the background for AMD development in elderly individuals with genetic predisposition. The main pathological changes associated with AMD vary with AMD stage and are described below.

\subsection{Early stage AMD}

Early AMD is characterized by thickening and loss of normal architecture within Bruch's membrane, lipofuscin accumulation in the RPE, and drusen formation beneath the RPE in Bruch's membrane (Fig. 1). The earliest pathological changes are the appearance of basal laminar deposits (BlamD) and basal linear deposits (BlinL) (Green and Enger, 1993). BlamD consist of membranogranular material and foci of wide spaced collagen between the plasma membrane and basal lamina of the RPE. BlinL consist of vesicular material located in the inner collagenous zone of Bruch's membrane and represent a specific marker for AMD (Curcio and Millican, 1999).

Drusen, derived from the German word for geodes, cavities in rocks often lined by crystals, are localized deposits lying beneath the basement membrane of the retinal pigment epithelium (RPE) into Bruch's membrane. Drusen in AMD are most frequently found as clusters within the macular region. They vary in size, shape, color, consistency, and distribution, and they tend to increase in number with advancing age. In the earliest stage, they may be visible ophthalmoscopically, when their diameter exceeds $25 \mu \mathrm{m}$ (Sarks et al., 1999), as semitranslucent punctate dots in retro-illumination. As the overlying RPE thins, drusen are more obvious as yellow-white deposits.

Clinically, drusen are classified morphologically either as hard or soft. Hard drusen, which are relatively common in elderly patients with or without AMD, appear clinically as small, 
yellowish, and punctuated deposits that are less than $63 \mu \mathrm{m}$ in diameter. The presence of drusen, especially drusen that are few in number and hard in quality, is not considered a particularly important risk factor for the development of AMD. In contrast, soft drusen, which are characterized by a more diffuse, paler and larger appearance, perhaps with 'fuzzy' or blurry edges, signify early AMD. The large drusen, bilateral drusen, and/or numerous drusen, are significant risk factors for development of late stage AMD. The larger the drusen, the greater the area they cover, and the larger the areas of hyperpigmentation and hypopigmentation of the RPE in the macula, the higher the risk of late age-related macular degeneration is (Klein et al., 2002).

The molecular and cellular constituents of drusen have been analyzed extensively (Anderson et al., 2004; Crabb et al., 2002; Hageman et al., 2001; Johnson et al., 2000; Mullins et al., 2000; Russell et al., 2000). Complement components, other inflammatory molecules, lipids, lipoproteins B and E, and glycoproteins are common constituents of ocular drusen (Johnson et al., 2002). Immunohistochemical analyses have shown various molecular constituents, such as apolipoproteins $\mathrm{B}$ and $\mathrm{E}$, different immunoglobulins, factor $\mathrm{X}$, amyloid $\mathrm{P}$ component, amyloid $\beta$, complement $C 5$ and $C 5 b-9$ terminal complexes, fibrinogen, vitronectin, and others, to be present in all phenotypes of hard and soft drusen (Anderson et al., 2004; Johnson et al., 2000; Mullins et al., 2000; Nozaki et al., 2006). Their precise functional role in the pathogenesis of AMD is not entirely clear, although it has long been recognized that drusen are the hallmark lesions of AMD.

\subsection{Late stage AMD}

The primary clinical characteristic of late stage 'dry' AMD is the appearance of RPE atrophy, usually known as geographic atrophy. Geographic atrophy is characterized by roughly oval areas of hypopigmentation and is usually the consequence of RPE cell loss. Loss of RPE cells responsible for servicing the overlying photoreceptors leads to the gradual degeneration of nearby photoreceptors, resulting in thinning of the retina (Fig. 2) and a progressive visual impairment. In severe cases, retinal atrophy may extend to the outer retinal layers including the outer plexiform and inner nuclear layers. Hyperpigmentary changes associated with compensatory RPE cell proliferation are frequently observed at the periphery of these hypopigmented areas (de Jong, 2006).

Choroidal neovascularization (CNV) is the defining characteristic of late stage 'wet' or neovascular AMD. Classical neovascular AMD is mainly illustrated with CNV and subretinal neovascular fibrous tissue (Fig. 3). The neovascularization has two etiologic patterns: (1) new vessels sprouting from the choroidal vessels, penetrating Bruch's membrane and growing into the subretinal space are the classical descriptions of wet AMD (Green, 1999), which is most common; and (2) vessels that are derived mainly from the retinal circulation in a process that has been called retinal angiomatous proliferations (RAP), also called deep retinal vascular anomalous complex or retinochoroidal anastomosis (Brancato et al., 2002;Donati et al., 2006; Ghazi, 2002; Hunter et al., 2004; Yannuzzi et al., 2001). RAP refers to new vessel development extending outward into the subretinal space from the neurosensory retina, sometimes anastomosing with the choroid-derived vessels (Lafaut et al., 2000). RAP, however, occurs much less frequently than the classical choroid-derived neovascular vessels.

\section{Single nucleotide polymorphisms and molecular pathology of AMD}

\subsection{Single nucleotide polymorphism}

With the sequencing of the human genome and improved DNA sequencing and mapping technologies, recent years have seen an explosion of genetic studies identifying single nucleotide polymorphisms (SNPs) which confer increased or decreased risk of disease (Smith, 
2005). AMD is no exception, as SNPs associated with inflammation, oxidative stress, angiogenesis, and other pathological processes have been linked to AMD. Investigation of the expression of these genes and their functional properties in AMD cases have led to a deeper understanding of the pathological mechanisms of AMD.

\subsection{Complement system}

While AMD is a highly complex disease with numerous intersecting etiological factors, recent studies have generated significant interest in the inflammatory underpinnings of AMD pathogenesis (Klein et al., 2008b). These studies have been buttressed by genetic studies identifying inflammation-associated SNPs that modulate AMD risk. These SNPs lie in genes encoding complement factors, chemokines and chemokine receptors, and toll-like receptors.

3.2.1. Complement factors and AMD pathology-The complement system of innate immune system includes over 30 proteins, which are activated by immune complexes, residues on microbial cell surfaces, and other triggers. Activation of the complement system generates a variety of pro-inflammatory responses, including the production of membrane-attack complexes (MAC) which lead to cell lysis, release of chemokines to mediate recruitment of inflammatory cells, and enhancement of capillary permeability (Walport, 2001a, b). While complement activity is crucial for the immune responses against pathogens or dying cells, dysregulation of the cascade can result in complement overactivation-mediated damage to nearby healthy tissue.

A number of studies have illustrated the presence of complement components and complement regulatory proteins in drusen and nearby RPE of AMD patients (Crabb et al., 2002; Hageman et al., 1999; Johnson et al., 2001; Johnson et al., 2000; Mullins et al., 2001; Nozaki et al., 2006), suggesting a role for complement in AMD pathogenesis (Bora et al., 2008). These studies have been matched by genetic association studies. Moreover, several studies have demonstrated that animal models with complement knockdown, either genetically or with pharmacological agents such as anti-complement antibodies, exhibit decreased CNV after laser injury, a commonly employed model for AMD-associated CNV in humans (Patel and Chan, 2008).

\subsubsection{Complement factor $\mathrm{H}$ (CFH)}

3.2.2.1. CFH SNP and AMD: $C F H$ is encoded within the interval of chromosome 1q23-32, a region associated with AMD previously through linkage studies (Klein et al., 1998). A major AMD-associated SNP is the $\mathrm{Y} 402 \mathrm{H}$ (tyrosine to histidine substitution at amino acid 402) variant of complement factor $H$ (CFH) (Edwards et al., 2005; Hageman et al., 2005; Haines et al., 2005; Klein et al., 2005). CFH is now widely accepted as an important AMD susceptibility gene, harboring variants and haplotypes associated with increased and reduced disease risk. CFH is identified in normal RPE and choroid (Klein et al., 2005).

$\mathrm{CFH}$ is a negative regulator of the complement system. The $\mathrm{C} 3 \mathrm{~b}-\mathrm{Bb}$ complex is a key component of the alternative pathway, and $\mathrm{CFH}$ inhibits the alternative pathway by promoting Factor I-mediated inactivation of $\mathrm{C} 3 \mathrm{~b}$ or by displacing Factor $\mathrm{Bb}$ from the $\mathrm{C} 3 \mathrm{bBb}$ complex (Alsenz et al., 1985). Given the abundance of complement components, including alternative pathway components, in drusen of AMD, it is possible that impaired complement inhibitory activity by $\mathrm{CFH}$ contributes to AMD pathogenesis.

The risk-conferring Y402H CFH variant (genotype CC) has also been reported to reduce the binding affinity to C-reactive protein (CRP), a pro-inflammatory molecule, as compared with the Y402Y variant (genotype TT). This suggests that reduced binding of CRP by CFH might lead to impaired targeting of CFH to cellular debris (Laine et al., 2007; Skerka et al., 2007). 
In comparing the $\mathrm{Y}$ and $\mathrm{H}$ variants of $\mathrm{CFH}$, $\mathrm{Yu}$ et al. also show no significant difference in their protein secretion, cofactor activity, or interaction with heparan, but a significant difference in binding to CRP (Yu et al., 2007). Moreover, elevated serum level of CRP has been shown to be associated with AMD (Mold et al., 1999; Seddon et al., 2004).

$\mathrm{CFH}$ dysfunction may lead to excessive inflammation and tissue damage involved in the pathogenesis of AMD (Johnson et al., 2006). Using confocal immunohistochemical analysis, Johnson and associates illustrated that individuals homozygous for the risk-conferring $\mathrm{Y} 402 \mathrm{H}$ $\mathrm{CFH}$ variant have higher levels of CRP in the choroid compared to individuals homozygous for the "normal" Y402 variant. In contrast, there is no significant difference between the two phenotypes (YY and $\mathrm{HH}$ ) in the amount of CFH protein in the RPE-choroid complex (Johnson et al., 2006). These results support the notion that the association between $C F H$ polymorphisms and AMD may involve CRP. For example, impaired binding of CRP by the risk-conferring $\mathrm{CFH}$ variant might lead to accumulation of $\mathrm{CRP}$ in the choroid. However, a recent publication indicates that $\mathrm{CFH}$ binds to the denatured rather than native CRP, thus casting some doubt upon this link between CFH and CRP (Hakobyan et al., 2008). It is also possible that persistent chronic inflammation that is a byproduct of attenuated complement-inhibitory activity may occur in those individuals with the risk-conferring CFH SNP Y402H and that this proinflammatory state, rather than impaired binding by $\mathrm{CFH}$, leads to CRP accumulation in AMD retina. Alternatively, the role of CFH in AMD might be completely independent of CRP. Without a doubt, further studies are necessary to dissect the role, if any, of the CFH $Y 402 \mathrm{H}$ SNP in AMD pathogenesis.

In addition to the CFH Y402H (dbSNP ID: rs 1061170) SNP, 5 other $C F H$ variants (rs3753394, rs800292, rs1061147, rs1061170, rs380390, and rs1329428) have been reported in AMD association studies. The three SNPs at rs1061147, rs1061170, and rs380390 are in complete linkage disequilibrium (LD). Among them, the rs 1061170 (Y402H) was the only SNP that leads to a non-synonymous amino acid change. These SNPs have been reported to be major genetic factors for developing AMD in Caucasians (Edwards et al., 2005; Hageman et al., 2005; Haines et al., 2005; Klein et al., 2005; Tuo et al., 2006). In the Chinese and Japanese populations, only three of these CFH SNPs-at rs1329428, rs800292 (I62V), and rs3753394, but not at rs1061170 (Y402H)-were associated with risk of exudative AMD (Chen et al., 2006; Okamoto et al., 2006). Thus, studies to date demonstrate an association between CFH and AMD. The particular SNPs associated with AMD, however, depend upon the study and the study population. It is possible that CFH could play a central role in AMD pathogenesis and that multiple SNPs that impact CFH function might contribute to the development of AMD.

\subsubsection{Association between the CFH SNP and Chlamydia pneumoniae infection:}

Recently, some studies have suggested a potential role for Chlamydia pneumoniae infection in AMD pathogenesis. AMD patients have been found to possess increased serum anti- $C$. pneumoniae antibodies, and these antibodies have been linked to increased risk of AMD progression (Robman et al., 2005). Moreover, C. pneumoniae has been found in AMD neovascular membranes (Kalayoglu et al., 2005).

C. pneumoniae is a potent activator of the alternative complement system and thus, its effects might be mediated through complement over-activation. This notion is supported by a recent study demonstrating that the presence of the risk-conferring $C F H$ variant and high $C$.

pneumoniae antibody titer significantly increases AMD risk, well beyond the risk associated with possessing either risk factor alone (Baird et al., 2008). Whether this interaction is synergistic or additive is unclear. Since C. pneumoniae is a trigger for the alternative complement pathway, it is possible that once triggered, the alternative pathway runs unabated in patients with the risk-conferring $C F H$ variant, leading to AMD pathogenesis. It is also possible that a low-grade inflammation from persistent $C$. pneumoniae infection may also 
predispose to AMD and that the contribution of $C$. pneumoniae and $\mathrm{CFH}$ to AMD may be simply additive.

We recently found no relationship between risk-conferring $C F H$ variant and $C$. pneumoniae in 148 advanced AMD patients and 162 control subjects with the infection, although there is a positive association between AMD and $C$. pneumoniae infection (20\% vs. $10 \%$ positive $C$. pneumoniae DNA detected in the blood of AMD patients compared with the controls) (Shen et al., 2008). Therefore, CFH may not be directly involved in the pathogenesis of $C$. pneumoniae infection-mediated AMD. Further studies are indeed warranted to determine whether a link exists between C. pneumoniae and CFH in AMD pathogenesis.

3.2.2.3. CFH SNP genotype and therapeutic responses: Analyzing the response to treatment in AREDS patients, Klein et al. recently observed an interaction between the $C F H \mathrm{Y} 402 \mathrm{H}$ genotype and supplementation with antioxidants and zinc. In individuals homozygous for the non-risk phenotype (Y402Y/Y402Y), 34\% of those treated with placebo progressed to advanced AMD, compared with $11 \%$ of those treated with antioxidants plus zinc, a reduction of approximately $68 \%$. In contrast, in individuals homozygous for the risk-conferring phenotype (Y402H/Y402H), 44\% of those treated with placebo group progressed to advanced AMD, compared with $39 \%$ of those treated with antioxidants plus zinc, a reduction of only $11 \%$ (Klein et al., 2008a). In addition, a similar interaction was observed in the groups taking zinc versus those taking no zinc: zinc intake had a more dramatic protective effect in patients with non-risk alleles, compared with patients with risk alleles. These results suggest that the zinc plus antioxidative treatment seems to have less impact on those with the high-risk $C F H$ variant. Similarly, Brantley et al. investigated 86 wet AMD patients to determine whether there is an association between $\mathrm{CFH}$ genotypes and response to treatment with intravitreal bevacizumab. The results show that only $10.5 \%$ of patients with the risk-conferring $\mathrm{Y} 402 \mathrm{H} /$ $\mathrm{Y} 402 \mathrm{H}$ phenotype demonstrated improved vision with treatment, compared with 53.7\% of patients with the $\mathrm{Y} 402 \mathrm{Y} / \mathrm{Y} 402 \mathrm{Y}$ and $\mathrm{Y} 402 \mathrm{Y} / \mathrm{Y} 402 \mathrm{H} C F H$ variants $(P=0.004)$ (Brantley et al., 2008). The underlying mechanism of this genotype-response association is still elusive, and more studies are warranted before any definitive conclusions are drawn.

3.2.3. Complement factor B (BF), complement component 2 (C2), C3, C7, and complement factor I (FI)_Complement component $2(C 2)$ is paralogous to complement factor $B(B F)$ and resides adjacent to $B F$ on chromosome 6p21.3, and haplotypes in $B F$ and $C 2$ have been linked to AMD. In particular, the $\mathrm{L} 9 \mathrm{H} B F / \mathrm{E} 318 \mathrm{D} C 2$ and $\mathrm{R} 32 \mathrm{Q} B F /$ intronic variants of $C 2$ have been shown to be protective for AMD (odds ratio $(\mathrm{OR})=0.45$ and 0.36 , respectively) by Gold et al. Gold and his colleagues hypothesized that the significance of the haplotypes is due largely to the $B F$ variants, which are in strong linkage disequilibrium with $C 2$. BF is a complement activating factor, and studies have demonstrated that at least one of the two variants associated with AMD-R32Q $B F$-leads to an impairment in the complement activating function of BF (Gold et al., 2006). Thus, much like impaired CFH-mediated complement inhibition confers AMD risk, decreased complement activation by BF might serve to protect against AMD risk.

Another functional polymorphism in the $C 3$ gene, R80G, on chromosome 19p13, has been associated with AMD. The wild type variant migrates slowly on electrophoresis (C3 slow, or $\mathrm{C} 3 \mathrm{~S})$. In contrast, the fast migrating allotype $(\mathrm{C} 3 \mathrm{~F})$, has been reported to be strongly associated with AMD in a study from English and Scottish populations (Yates et al., 2007). C3F has in fact been associated with several diseases, including membranoproliferative glomerulonephritis type II (Montes et al., 2008). This glomerulonephritis shares some similarities with AMD—namely, a role for uncontrolled alternative complement activation as well as the accumulation of complement-containing extracellular deposits. The deposits in membranoproliferative glomerulonephritis are key features of the disease and are located in 
the glomerular basement membrane of the kidney (Finn and Mathieson, 1993; Pickering et al., 2002). A major C3-regulated factor is the complement factor I (FI). FI is involved in the degradation of the $\mathrm{C} 3 \mathrm{~b}$ component of the $\mathrm{C} 3 \mathrm{bBb}$ complex of the alternative pathway. Variation near the FI gene on chromosome 4q25 is associated with risk of advanced AMD, although no obvious functional variation has been discovered (Fagerness et al., 2008).

These incipient studies on the role of complement in AMD have paved the way for identifying other genes in the complement pathway potentially associated with AMD. One study reported that C7 (rs2876849) is protective for AMD development in Caucasians (Dinu et al., 2007). Moreover, the SNP variant rs2511989 located in the SERPING1 gene encoding the complement component 1 (C1) inhibitor was recently reported to occur less frequently in AMD cases than in control subjects (Ennis et al., 2008). Taken together, while more extensive studies are necessary to delineate the specific roles (if any) of these complement components in AMD, the current data suggest a central role for innate immunity and inflammation in general and complement overactivation in particular for AMD pathogenesis.

\subsection{Chemokines and chemokine receptors}

Chemokines play a central role in recruitment of immune cells to inflamed tissues. These chemokines bind to chemokine receptors on inflammatory cells such as macrophages to promote the mobilization of these cells out of circulation and into tissues. One chemokine receptor that has generated much interest in AMD is CX3CR1. The CX3CR1 chemokine receptor is a G-coupled receptor found on a variety of inflammatory cells, including microglia, macrophages, T-cells, and astrocytes. When bound by its ligand, CX3CL1 (also known as fractalkine), CX3CR1 mediates mobilization of leukocytes to inflamed tissues and subsequent activation of these inflammatory cells (Fong et al., 1998). Both CX3CR1 and CX3CL1 are rich in the retina and brain (Combadiere et al., 1998; Foxman et al., 2002).

3.3.1. CX3CR1 SNP and AMD-CX3CR1 is encoded in chromosome $3 \mathrm{p} 21.3$ in human. We have reported that the V249I (valine to isoleucine at amino acid 249) and T280M (threonine to methionine at amino acid 280) CX3CRI SNPs confer increased risk of AMD (Tuo et al., 2004). The OR (CI) of these two SNPs were 1.86 (1.04-3.31) for V249I and 1.94 (1.02-3.69) for T280M. In a French study, homozygosity for the CX3CR1 T280M allele was also reported to be associated with AMD (Combadiere et al., 2007). We have also compared expression of CX3CR1 mRNA and protein in AMD macular cells obtained from archived paraffin-embedded tissue sections (Chan et al., 2005). This previous study showed that CX3CRI transcript and protein in the AMD maculae were undetectable or expressed at much lower levels than their SNP-type counterparts in the normal eyes. In normal eyes, macular cells from an individual bearing "at risk" allele T/M280 exhibited lower $C X 3 C R 1$ transcript expression than an individual bearing "wild type or major" allele T280T. Moreover, we found lowered $C X 3 C R 1$ expression in the macula compared with the perimacular retina of AMD eyes bearing T280M. In contrast, similar levels of $C X 3 C R I$ expression were detected in macular and perimacular regions of the normal subjects, which suggested that $C X 3 C R I$-mediated decreases in inflammatory cell chemokinesis might contribute to age-related changes in the macula (Chan et al., 2005; Tuo et al., 2004) (Fig. 4). These results are supported by the recent study by Combadiere and colleagues, whose immunohistochemical analysis in humans showed that CX3CR1 was expressed on all retinal microglial cells, and these cells are the only cells in the retina that express CX3CR1. Their immunohistochemical analysis of AMD cases suggest that CX3CR1-positive microglial cells accumulated subretinally in affected areas of the macula, and they may determine particular pathological conditions to stimulate AMD development (Combadiere et al., 2007). 
3.3.2. Other chemokines, cytokines and toll-like receptors-The interleukin-8 (IL8) A251T genetic polymorphism located in chromosome 4q13-21 is reported to be associated with AMD, with the homozygous AA genotype (A allele) as the "at risk" factor (Goverdhan et al., 2008). The AA genotype has also been shown to induce angiogenesis in rat cornea (Koch et al., 1992). The IL8 251AA genotype is postulated to act by influencing IL8 production, or, alternatively, through linkage disequilibrium with functional variants elsewhere in the IL8 loci or in neighboring genes. In the same study, SNPs in other pro-inflammatory chemokines including interleukin-1 $\beta$ (IL1 $\beta$ ) C511T, interleukin-6 (ILO) C174G and the antiinflammatory cytokine $I L 10$ G1082A were analyzed and showed no significant association with AMD (Goverdhan et al., 2008). Taiwan Chinese carriers of the IL8 C781T variant, independent to the $C F H \mathrm{Y} 402 \mathrm{H}$ variant, have also been shown to be at increased risk of developing wet AMD (Tsai et al., 2008).

The Toll-like receptor (TLR) family consists of 10 receptors that play a critical role in innate immunity. These receptors differentiate between a broad range of microbial molecules to induce an appropriate immune response by tissue and inflammatory cells. TLR4, for example, recognizes the lipopolysaccharide component of bacterial cell walls. Association with a microbial component triggers upregulation of pro-inflammatory genes such as tissue necrosis factor, interleukin-1 $\beta$, and interleukin-6, through the NF-kB pathway (Misch and Hawn, 2008). Moreover, TLR4 has also been implicated in photoreceptor outer segment handling and phagocytosis by RPE cells (Kindzelskii et al., 2004). A study by Zareparsi et al reported that the D299G (aspartate to glycine at amino acid 299) TLR4 (encoded in chromosome 9q32-33) polymorphism leads to increased AMD risk $(\mathrm{OR}=2.65)$ (Zareparsi et al., 2005). Subsequent studies, for example by Despriet and Edwards, however, demonstrated no significant association of the D299G TLR4 SNP with AMD risk (Despriet et al., 2008; Edwards et al., 2008). Functionally, the D299G TLR4 variant has been linked to impaired LPS responsiveness in mice, which is reversible by TLR4 overexpression (Arbour et al., 2000). It is possible, then, that if TLR4 is, indeed, linked to AMD, presence of the D299G TLR4 variant leads to impaired response to and clearance of microbes, which might facilitate ongoing low-grade inflammatory state leading to pathological changes seen in AMD. Given the conflicting studies to date, however, considerable studies are necessary to clarify whether TLR4 is implicated in AMD pathogenesis.

The $\mathrm{L} 412 \mathrm{~F}$ variant of the $T L R 3$ gene (i.e. a leucine to phenylalanine change at amino acid 412 ), encoded by the T allele at rs 3775291 of the TLR3 gene, has been reported in three case-control cohorts to be protective against dry AMD, possibly through suppression of RPE apoptosis (Yang et al., 2008). However, other investigators have been unable to confirm this association (Edwards et al., 2008; Kaiser, 2008). After genotyping 68 SNPs across the TLR genes in a cohort of 577 subjects, with and without AMD, in two additional cohorts used for replication studies, Edwards and colleagues report that TLR3, TLR4, and TLR7 are unlikely to have major impact on overall AMD risk (Edwards et al., 2008). Further analyses of more cohorts or reanalyses of the above cohorts with absolutely normal controls could help to clarify the association of TLR with AMD (Edwards et al., 2008; Kaiser, 2008).

In general, the relationships of these SNPs with AMD are still preliminary or controversial to date and require additional studies in diverse and larger populations. If further molecular epidemiological investigations support these variants in AMD, functional studies should be performed to verify the role of their risk-conferring variants in AMD pathogenesis.

\subsection{LOC387715/ARMS2 and HtrA1}

A genome-wide scan and genetic linkage analysis of 70 families with AMD suggests that chromosome 10q26 may contain a common AMD gene (Majewski et al., 2003). This finding of an AMD susceptibility locus on chromosome 10q26 has been replicated by other genome- 
wide linkage studies (Weeks et al., 2004) and supported by a genome-scan meta-analysis (Fisher et al., 2005). Later, a focused SNP genotype study of AMD families and a case-control cohort study also found a strong association overlying three genes at 10q26. The association was strongest over two nearby genes, LOC387715/ARMS2 (age-related maculopathy susceptibility 2, or ARMS2) and a secreted heat shock serine protease (high temperature required factor A-1, HTRA1) (Jakobsdottir et al., 2005). Although there is strong linkage disequilibrium (LD) across these two genes, these two genes seem to play different putative functional roles and are expressed in different patterns in retina with or without AMD. Therefore, we discuss them separately.

3.4.1. ARMS2 SNP and AMD-The association of ARMS2 gene with AMD, especially advanced AMD, susceptibility has now been replicated in numbers of independent studies (Conley et al., 2006; Rivera et al., 2005; Ross et al., 2007; Schmidt et al., 2006; Seddon et al., 2007; Kanda et al., 2007). The risk-conferring ARMS2/LOC387715 SNP, A69S, is associated with AMD. Heterozygozity at the ARMS2/LOC387715 (A69A/A69S) is associated with odds ratio (OR) of 1.69-3.0 for advanced AMD, while homozygosity for the risk conferring allele (A69S/A69S) results in an OR of 2.20-12.1, after controlling for demographic and behavioral risk factors (Ross et al., 2007). Our data, including a population-based study (Wang et al., 2008), and data by Jakobsdottir and colleagues (Jakobsdottir et al., 2005) have both shown that the frequency of the ARMS2 risk allele is higher in patients with advanced AMD than in those with early or intermediate AMD. Interestingly, an even stronger effects on AMD risk has been noted in patients with both the risk-conferring ARMS2 variant and elevated serum levels of several inflammatory markers including CRP, IL-6, soluble intercellular adhesion molecule 1 (sICAM-1) (Wang et al., 2008).

More recently, Fritsche et al. showed that a deletion-insertion polymorphism (*372_815delins54), which resides within the 3'-UTR of the ARMS2 gene, also associates very significantly with AMD (Fritsche et al., 2008). In this deletion-insertion polymorphism variant, the deletion removes the polyadenylation signal sequence at position $* 395 \_400$ exclusively used for the addition of a poly(A) tract $19 \mathrm{bp}$ downstream. The insertion introduces a 54-bp AU-rich element, known for its properties to control mRNA decay in many transcripts that encode a wide variety of proteins involved in transient biological processes (Barreau et al., 2005; Garneau et al., 2007; Khabar, 2005). As a consequence, expression of ARMS2 in homozygous carriers of the deletion-insertion variant is absent, or at least sufficiently low to be experimentally undetectable. Most importantly, since the A69S and InDel are in 100\% LD and on the same haplotype, the effects are not independent to each other.

3.4.2. ARMS2 expression-ARMS2 is highly expressed in placental tissue, but only limited biological properties have been attributed to it until recently. Kanda et al. reported that ARMS2 is localized to the ellipsoid region of the photoreceptors in retina, where most of the mitochondria are located (Kanda et al., 2007). Recently, Fritsche et al. correlated the ARMS2 SNPs to ARMS2 expression level (Fritsche et al., 2008). Immunoblot analysis in human placentas showed that ARMS2 is expressed in individuals with one or two non-risk haplotypes but not in homozygous carrier of the insertion-deletion ARMS2 risk variant. Fritsche et al. also showed that ARMS2 protein in the human retina localizes to the photoreceptor layer and that it demonstrates a minor dot-like staining in the ellipsoid region of the rod and cone inner segments, which fully co-localizes with a mitochondrial marker, anti-MTCO2, suggesting that ARMS2 is expressed in the mitochondria (Fritsche et al., 2008).

3.4.3. ARMS2 and mitochondria-Mitochondria are the major source of superoxide anion in the cell. The superoxide anion generates highly toxic hydroxyl radicals and hydrogen peroxide that damage the cell by reacting with proteins, DNA, and lipids and ultimately, by inducing cell death. Several lines of evidence indicate that mitochondria play a central role in 
aging and in the pathogenesis of AMD. First, studies have shown that human donor AMD eyes contain higher levels of protein adducts resulting from the oxidative modification of carbohydrates and lipids (Crabb et al., 2002; Howes et al., 2004) and higher levels of antioxidant enzymes (Decanini et al., 2007; Frank et al., 1999) compared with non-AMD eyes, which indicate that oxidative stress plays an important role in AMD. Second, converging evidence has suggested that DNA damage occurs more readily in the mitochondrial than the nuclear genome, and that mitochondrial DNA (mtDNA) damage could lead to RPE dysfunction. Blue light irradiation and treatment with hydrogen peroxide cause long-lasting mtDNA but not nuclear DNA mutations in cultured RPE cells (Ballinger et al., 1999; Godley et al., 2005). Moreover, mtDNA damage accumulates in the retina and RPE with age (Barron et al., 2001).

Recently, several studies offered direct evidence of mitochondrial alterations in AMD (Feher et al., 2006; Nordgaard et al., 2006, 2008). Similar to findings by Feher and colleagues (Feher et al., 2006), we have also found a drastic decrease in normal mitochondria in the photoreceptors and RPE cells of the AMD eyes as compared to that of the normal age-control eyes (Fig. 5).

3.4.4. HtrA1 SNP and AMD-The HtrAl gene is located on chromosome 10q26.3, extremely close to the locus at $A R M S 2,10 \mathrm{q} 26.13$. Indeed, as described above, these two genes are in strong linkage disequilibrium. To date, four significant SNPs have been reported in the promoter and the first exon of HtrAl: rs11200638 (G625A), rs2672598 (T487C), rs1049331 (C102T, A34A), and rs2293870 (G108T, G36G). Several studies have shown that rs11200638 in the promoter region is the most well-documented, statistically significant AMD-associated SNP with a high OR of 1.60-2.61 and 6.56-10.0 in heterozygous and homozygous individuals (Caucasians, Chinese and Japanese), respectively (Cameron et al., 2007; Deangelis et al., 2008; Dewan et al., 2006; Mori et al., 2007; Tam et al., 2008; Yang et al., 2006). Mori et al. showed that presence of the A allele at rs11200638, which is the risk allele, was associated in subtype analyses with wet AMD (Mori et al., 2007). Later, Cameron et al. found that rs11200638 was also significantly associated with geographic atrophy (Cameron et al., 2007). By examining four cohort studies, we have also confirmed this association with ORs of 2.17 and 2.97 for dry and wet AMD, respectively (Tuo et al., 2008). In addition, recent studies have shown that there is an observable increase in population attributable risk (about 5.5-fold increase) by the joint effect of smoking and the HtaAl risk allele, indicating that smokers homozygous for the risk allele had a substantially higher risk of developing wet AMD than non-smokers with the risk allele (Tam et al., 2008). This finding is in accordance with a previous study by Schmidt and colleagues where smoking significantly increased the risk of AMD in patients with the A69S variant in LOC387715 (Schmidt et al., 2006). In contrast, Deangelis et al. reported that although the HtrAl SNP was significantly associated with wet AMD, no interaction was found between this SNP and smoking in a phenotypically welldefined cohort of 268 subjects including 134 extremely discordant sibpairs (Deangelis et al., 2008).

3.4.5. HtrA1 expression-HtrA1 is a stress-inducible member of a family of heat shock serine proteases, which is involved in the modulation of various malignancies and diseases such as Duchenne muscular dystrophy and osteoarthritis (Grau et al., 2006). As rs 11200638 is located within a CpG island of the proximal promoter, 512 bp upstream of the HtrAl transcription start site, the risk allele "A" of HtrAl SNP was shown to enhance HtrAl transcription in vitro in RPE cell lines (Dewan et al., 2006). In the same study, individuals homozygous for the risk allele (genotype AA) expressed higher levels of HtrA1 in their circulating lymphocytes in vivo, compared with individuals homozygous for the non-risk variant (genotype GG). In vivo HtrA1 is expressed in a variety of human tissues and cells, including the RPE and vascular endothelium (Chan et al., 2007). Elevated expression of 
HtrAl mRNA and/or protein in the drusen and CNV components in AMD patients carrying the AA risk genotype has been reported in several studies (Cameron et al., 2007; Chan et al., 2007; Tuo et al., 2008; Yang et al., 2006) (Fig. 6).

Preliminary evidence suggests that HtrA1 plays dual functions in extracellular protein degradation and in cellular growth or survival. In chronic inflammatory conditions, extracellular protease activities of HtrA1 may favor neovascularization by enhancing degradation of extracellular matrix components through increased expression of matrix metalloproteinases (Grau et al., 2006), or by binding to transforming growth factor (TGF)- $\beta$, an angiogenic factor whose expression has been geographically and temporally linked to CNV (Ogata et al., 1997; Oka et al., 2004). HtrA1 is also a secretory protein and an inhibitor of TGF$\beta$ family member (Oka et al., 2004). TGF- $\beta$ controls a plethora of neural and glial function throughout life. Blockage of the proteolytic activity of HtrA1 leads to a restoration of TGF- $\beta$ signaling and subsequent neuronal death, suggesting that HtrA1 could play a critical role in controlling TGF- $\beta$ dependent neuronal survival (Launay et al., 2008). TGF $\beta$ also is a potent inhibitor for immune response (Lehner, 2008; Wahl, 2007).

Overall, the biological functions and potential role of the $H t r A l$ promoter SNP in AMD remain exploratory and speculative. Further studies on the possible mechanisms of this susceptibility gene may provide information on variable phenotypes, new preventive strategies, and therapeutic options for AMD.

3.4.6. ARMS2/HtrA1-Much debate exists as to whether ARMS2, HtrAl, or both are responsible for the AMD susceptibility from chromosome 10q26. Recently Kanda et al. reported that ARMS2 (T allele at rs 10490924, A69S), rather than HtrAl, to be truly associated with AMD (Kanda et al., 2007). Their data show that the A69S ARMS2 SNP is best explained the AMD susceptibility associated with the AMD locus at chromosome 10q26. Moreover, in a Chinese cohort study evaluating patients with wet AMD and control subjects, ARMS2 was slightly more associated with AMD than HtrAl SNP, and they were in the same linkage disequilibrium block (Dewan et al., 2006). Another report also supports the notion that the ARMS2 variant is an independent risk factor for neovascular AMD (Shuler et al., 2008).

Although the exact biological roles of both the ARMS2 and HtrAl genes in humans are unclear, SNP analyses have confirmed their association with AMD. It is possible that these SNPs, which contribute to AMD development and are located on one haplotype, may act independently or interact with other genes related to AMD, not only on genetic but also protein levels. It is also possible that ARMS2 and its pathway may be linked to mitochondrial oxidative stress, while HtrA1 and its pathway may be involved in the regulation of cell survival via chaperon/proteases (Clausen et al., 2002), and the inhibition of immune response via TGF- $\beta$ (Launay et al., 2008).

\subsection{Apolipoprotein E (ApoE)}

Apo-E is a structural component of plasma chylomicrons, very low-density lipoproteins (VLDL), and a subclass of high-density lipoproteins (HDL), and is synthesized in many tissues including the spleen, kidneys, lungs, adrenal glands, liver, and brain (Shanmugaratnam et al., 1997). The primary physiological role of ApoE is to facilitate the binding of LDL to LDL receptors on cellular membranes, thereby regulating the uptake of cholesterol required by cells. For instance, when large amounts of lipids are released from degenerating neuronal cellular membranes, the lipid materials can stimulate the astrocytes to synthesize ApoE, which binds these excess lipids and redistributes them for reutilization in cell membrane biosynthesis. Based upon this fact, Klaver et al. have speculated that an active biosynthesis of ApoE is required to support the high rate of photoreceptor renewal in the macular region (Klaver et al., 1998). 
3.5.1. ApoE SNP and AMD-The ApoE gene is located on chromosome 19q13.2 and is polymorphic, with three common isoforms: E2, E3, and E4. These three isoforms are coded by three different alleles: the ancestral E3 and the SNPs E2 and E4 (Schmidt et al., 2002). ApoE polymorphisms have already been linked to several neurodegenerative diseases, including Alzheimer disease, and prion diseases (Krasnianski et al., 2008; Tzourio et al., 2008). The Rotterdam Study in the Netherlands reported a protective role for the ApoE4 SNP $(\mathrm{OR}=0.45)$ and a slight risk-conferring role for the ApoE2 SNP $(\mathrm{OR}=1.5)$ (Klaver et al., 1998). Based on the role of ApoE in recycling of cholesterol and lipids for cell-membrane biosynthesis after neuronal injury, these polymorphisms have been speculated to impact retinal membrane renewal and affect macular integrity. Several studies later confirmed a role for ApoE SNP in AMD (Baird et al., 2006; Jun et al., 2005; Kovacs et al., 2007; Schmidt et al., 2002; Souied et al., 1998; Zareparsi et al., 2004), while others found no effect (Kaur et al., 2006; Schmidt et al., 2005; Schultz et al., 2003; Wong et al., 2006). We have also found the association between ApoE112R (E4) and a decreased risk of AMD development, and the underlying mechanisms might involve differential regulation of both CCL2 and VEGF by the ApoE isoforms (Bojanowski et al., 2006). However, a large, population-based, cross-sectional study $(n=10,139)$ using participants from the Atherosclerosis Risk in Communities Study found no association between AMD and any of the ApoE alleles in Australia (Kaur et al., 2006; Schmidt et al., 2005; Schultz et al., 2003; Wong et al., 2006).

3.5.2. ApoE expression-In AMD patients, the presence of ApoE has been illustrated in drusen (Shanmugaratnam et al., 1997). Ishida et al. also showed that AMD macula exhibit increase ApoE staining in drusen and basal laminar deposits. They have further demonstrated that RPE cells secrete ApoE in response to a variety of hormones, and that the secreted ApoE is associated with HDL. These findings suggest a possible role for ApoE in AMD pathology via retinal lipid trafficking (Ishida et al., 2004). Therefore, aging or disease-related disruption of normal ApoE function may result in the accumulation of lipoproteins between RPE and Bruch's membrane, which is consistent with lipid deposits in drusen. Indeed, the lipid deposits of drusen are often composed of cholesteryl esters and unsaturated fatty acids. Accumulation of drusen-associated lipid due to the impaired ApoE function could potentially affect the functional integrity of Bruch's membrane. Furthermore, the ApoE profile might influence the transport, capture, and stabilization of other key molecules, such as lutein and zeaxanthin, in the macula to ultimately accelerate the aging process and AMD development (Ong et al., 2001).

\subsection{VEGF}

It is well established that the formation of blood vessels occurs by angiogenesis and that vascular endothelial growth factor (VEGF) is a key molecule in promoting angiogenesis (Ferrara et al., 2003). VEGF can potentially induce vascular leakage and inflammation by triggering the increased production and permeability of capillary endothelial cells. The VEGF family currently includes VEGF-A, -B, -C, -D, -E, -F and placenta growth factor (PIGF), that bind in a distinct pattern to three structurally related receptor tyrosine kinases, denoted VEGF receptor-1, -2, and -3. Increased expression of VEGF-A in the RPE and in the outer nuclear layer is reported in post-mortem maculae obtained from individuals with AMD (Kliffen et al., 1997). VEGF plays a critical role in the pathogenesis of neovascular AMD, and recently, therapies targeting VEGF have shown promising results of significant improvement of central vision and reduction of CNV (Wylegala and Teper, 2007).

3.6.1. VEGF-A SNP and AMD-The VEGF-A gene is located on human chromosome 6p21 and is highly polymorphic. At least six polymorphisms in the $V E G F-A$ gene are detected to alter the levels of VEGF transcript expression: C2578A, G1154A, and T460C in the promoter 
region; $\mathrm{C} 405 \mathrm{G}$ and $\mathrm{C} 674 \mathrm{~T}$ in the 5'-untranslated region; and C936T in the $3^{\prime}$-untranslated region (Churchill et al., 2006).

Several studies have documented a significant association between variants in the VEGF-A gene and the risk of AMD. Neovascular AMD was found to be associated with the rs2010963 (G634C) VEGF-A SNP in a case-control cohort, and in a family cohort with two intronic $V E G F-A$ SNPs (rs833070 and rs3025030) (Haines et al., 2006). Another study, which involved 45 patients with neovascular disease, identified a haplotypic association in both the promoter and an intronic region of the VEGF gene (Churchill et al., 2006). Lin et al. genotyped five VEGF-A polymorphisms: C2578A, T460C, C405G, C674T, and C936T in a Chinese population study and found that only the VEGF C936T SNP was significantly increased in wet AMD (Lin et al., 2008). However, Richardson et al. (2007) provided a thorough tag-SNP based examination and found little evidence to support an association of the VEGF-A gene with AMD. Several other reports also showed no association between wet AMD and the VEGF gene (de Jong et al., 2007; Smith et al., 2007). These conflicting data could result from differences of the ethnicities studied, study designs, and statistical analyses.

3.6.2. VEGF-A SNP genotype and therapeutic responses-Currently several new therapeutic options targeting VEGF are available for wet AMD (Rosenfeld et al., 2006). Pegaptanib (macugen), an oligonucleotide aptamer that targets the VEGF165 isoform, and ranibizumab (Lucentis) and bevacizumab (Avastin), both monoclonal antibodies against VEGF-A, are currently employed in AMD therapy (Ferrara et al., 2006; Kaiser, 2006). Although VEGF SNPs may not be strongly associated with AMD, they might nevertheless contribute to the effectiveness of the anti-VEFG treatment. If so, pharmacogenetics studies may help us to determine which patients are likely to benefit from such anti-VEGF therapies.

\subsection{ERCC6}

ERCC6, a DNA repair gene, is located at chromosome 10q11. This gene is involved in excision repair of DNA and is responsible for Cockayne syndrome. The ERCC6 SNP C6530G is in the 5' flanking region. One study has demonstrated that the ERCC6 C6530G SNP is modestly associated with AMD susceptibility, its interaction with a SNP (rs380390) in the $C F H$ intron is highly associated with AMD (Tuo et al., 2006). A disease OR of 23 was conferred by homozygosity for risk alleles at both ERCC6 and $C F H$ compared with homozygosity for nonrisk alleles.

Enhanced ERCC6 expression is observed in lymphocytes from healthy donors bearing ERCC6 C6530G alleles (Tuo et al., 2006). The strong AMD predisposition conferred by the ERCC6 and $C F H$ SNPs may result from biological epistasis, because ERCC6 functions in universal transcription as a component of RNA pol I transcription complex. Intense immunoreactivity of ERCC6 is observed in AMD eyes from ERCC6 C6530G carriers. Overexpression of a single element in an enzyme complex can adversely impact complex functionality (Rinne et al., 2004). These data suggest that DNA repair mechanisms may play a role in AMD pathogenesis.

\subsection{ATP-binding cassette sub-family, member 4 (ABCA4)}

Recessively inherited Stargardt's disease is associated with mutations in a ATP-binding cassette sub-family, member 4 (ABCA4) gene on chromosome 1p21 that encodes rim protein, an ATP-binding transporter in the rims of photoreceptor outer segment disks (Azarian and Travis, 1997). Given clinical similarities between Stargardt's disease and AMD, such as central vision loss, progression RPE and photoreceptor atrophy, and the presence of retinal deposits, Allikmets and his colleagues investigated $167 \mathrm{AMD}$ patients to demonstrate whether mutations in the $A B C A 4$ gene might also contribute to AMD pathogenesis. They identified variants in 
one allele of the gene in 16\% of the AMD patients (Allikmets, 1997; Allikmets et al., 1997). Clinically, late onset Stargardt cases can be misdiagnosed as AMD, especially when basing diagnosis solely on photographic grading. It is possible that some of the association seen in the Allikmets et al. (1997) study reflects misdiagnosis of Stargardt's disease, which has previously been shown to be associated with $A B C A 4$, as AMD. Moreover, multiple subsequent studies showed little or no relation of $A B C A 4$ mutations with AMD (Bojanowski et al., 2005; De La Paz et al., 1999; Souied et al., 2000; Stone et al., 1998). Without doubt, further studies are required to clarify whether the $A B C A 4$ gene influences AMD development.

\section{Involvement of inflammatory cells}

AMD is a multifactorial disease that affects primarily the photoreceptors and RPE cells. The RPE cell is a specialized neural cell originated from neuroectoderm that provides metabolic support mainly to photoreceptor cells and is close to the inner thin basal membrane of the Bruch's membrane, which interposed between the RPE and choriocapillaries. In normal eye physiology, the cells of the RPE are essential for the maintenance of retinal homeostasis. Both photoreceptors and RPE cells exhibit age-related changes such as the size and shape of the cells, their nuclei and the pigment granules for RPE cells, especially on the molecular level, as well as AMD-specific changes.

There is ample evidence that inflammation plays an important role in both dry and wet AMD. Recently, Nussenblatt and Ferris posited the importance of the Downregulatory Immune Environment (DIE) in the eye (Nussenblatt and Ferris, 2007). This theory posits that the natural environment of the eye is designed to downregulate inflammation, thereby maintaining equilibrium in the eye. Therefore, any defect in the eye can disrupt the DIE, resulting in an overexuberant immune response in the eye (Nussenblatt and Ferris, 2007). Indeed, the RPE cell is one of many systems that downregulate the immune response in the eye, and thus the pathway between RPE damage and ocular inflammation is likely a two way street whereby RPE damage potentiates inflammation, which further worsens RPE degeneration.

\subsection{Macrophages}

While AMD is not a classic inflammatory disease like uveitis; inflammatory cells, in particular the macrophages, have been histologically demonstrated near AMD lesions, including in areas of Bruch membrane breakdown, RPE atrophy, and choroidal neovascularization (Coleman et al., 2008; Dastgheib and Green, 1994; Green, 1999; Grossniklaus et al., 2002; Lopez et al., 1993; Penfold et al., 2001). Moreover, macrophages can secrete various chemokines, which are implicated in AMD models of $\mathrm{Ccl}^{-/-}$and $\mathrm{Ccr}^{-/-}$murine models of AMD (see Section 5 below).

4.1.1. Macrophages in CNV-Several groups have demonstrated the presence of macrophages at neovascular membranes in wet AMD (Dastgheib and Green, 1994; Grossniklaus et al., 2002; Penfold et al., 2001). Moreover, macrophages in CNV lesions have been shown to express proangiogenic factors such as VEGF and tissue factor (Csaky et al., 2004; Grossniklaus et al., 2002).

While the presence of macrophages at CNV lesions is largely recognized, the role of these macrophages presents some controversy as to whether these macrophages serve an adaptive role to combat $\mathrm{CNV}$ or a causative role in inducing $\mathrm{CNV}$. Two groups have investigated the role of macrophages in AMD using dichloromethylene diphosphonate $\left(\mathrm{Cl}_{2} \mathrm{MD}\right)$-containing liposomes. When $\mathrm{Cl}_{2} \mathrm{MD}$-containing liposomes are ingested by macrophages, the toxic $\mathrm{Cl}_{2} \mathrm{MD}$ enzyme is released, resulting in macrophage death. Espinosa-Heidmann et al. (2003) and Sakurai et al. (2003) and their colleagues showed that when administered to mice, these liposomes markedly impaired macrophage recruitment to areas of laser retinal injury. 
Decreased macrophage accumulation at laser injury sites correlated with less severe laserinduced $\mathrm{CNV}$, as determined by fluoroscein angiography and histology.

On the other hand, Apte and colleagues, using a model of interleukin-10 (IL-10) deficient mice, found that macrophages play a protective role in CNV (Apte et al., 2006). They demonstrated that $I L-10^{-1-}$ mice exhibit increased recruitment of macrophages, resulting in decreased susceptibility to laser-induced CNV, suggesting a beneficial anti-CNV role for macrophages. This effect was blocked by inhibition of macrophage entry by anti-CD11b antibodies, antiF4/80 antibodies, or IL-10 supplementation. They also showed that IL-10 transgenic mice had decreased macrophage recruitment to the retina and developed more severe laser-induced CNV lesions. Furthermore, macrophages were capable of killing CD95+ cells and interacting with CD95L to mediate the development of laser-induced CNV. To address the discrepancies between their findings and earlier work by Sakurai and Espinosa-Heidmann, Apte and colleagues reported that the $\mathrm{Cl}_{2} \mathrm{MD}$-containing liposomes could penetrate $\mathrm{CNV}$ endothelial cells and directly damage CNV endothelium. They reported that the decreased CNV reported by Espinosa-Heidmann et al. and Sakurai et al. might therefore be secondary to the direct injury to CNV endothelium, rather than the depletion of macrophages (Apte et al., 2006).

4.1.2. A dual role for macrophages in AMD-Another plausible explanation for these seemingly contradictory findings is that macrophages comprise a heterogeneous group with a spectrum of phenotypes and activities (Mantovani et al., 2004). There are two subtypes of macrophages: the pro-inflammatory M1 macrophages, and the relatively anti-inflammatory M2 macrophages, which function scavenging and tissue remodeling. Therefore, it is possible that M2 macrophages in early stages perform the beneficial, long-term housekeeping role of scavenging deposits such as cleaning drusen. In contrast, M1 macrophages might induce and compound the inflammatory responses to the retinal injury by the laser, accelerating CNV development (Mantovani et al., 2004). Further investigation is warranted to determine whether macrophage polarization plays a role in AMD and CNV pathogenesis, and if so, to clarify the specific activities of these macrophage subtypes at various stages of AMD.

\subsection{Microglia}

Microglia are the resident immune cells in the retina required for neuronal homeostasis and innate immune defense (Langmann, 2007). They enter the retina during embryological development and are activated by retinal injury and degeneration, leading to the transformation of quiescent stellate-shaped microglia into large ameboid bodies. These activated microglia proliferate, migrate to areas of injury, phagocytize debris, and secrete pro-inflammatory cytokines and chemokines, as well as neurotoxins (Langmann, 2007). Indeed, histological analysis of AMD retinas has depicted the presence of many activated microglia in the macular lesions (Gupta et al., 2003).

As described above, the $C X 3 C R 1$ chemokine receptor found on microglia has been shown to harbor SNPs (T280M and V249I) that have been associated with increased risk of AMD in some reports (Chan et al., 2005; Tuo et al., 2004). Importantly, more studies that replicate these findings are necessary to confirm the association between $C X 3 C R 1$ and AMD.

The $C X 3 C R 1$ SNP is associated with impaired microglial chemotaxis (Combadiere et al., 2007). Since microglia are already present in the retina since embryological development and do not chemotactically enter the retina, these SNPs might lead to impaired microglial migration or egress from the retina, resulting in accumulation of microglia. These accrued microglia might cause direct damage to the photoreceptors. This is supported by at least one study demonstrating photoreceptor cell injury after administration of activated microglia to healthy photoreceptors (Roque et al., 1999). The findings from the $\mathrm{Cx}_{3} \mathrm{crl}^{-1-}$ murine model of AMD 
developed by Combadiere et al. also show that microglia play an important role in subretinal lesions (Combadiere et al., 2007), which we have discussed in further detail above.

\section{Animal models of AMD}

\subsection{Introduction}

Many efforts have been made to establish animal models that mimic human AMD. The development of a suitable model facilitates the identification of risk factors for disease development, elucidates fundamental molecular mechanisms underlying disease progression, and provides valuable guidance as to whether or not a particular treatment is a potentially safe and effective option for humans. The mouse is a genetically well-defined species, and the techniques for engineering the mouse genome are well developed and fairly reliable. Moreover, the methods for evaluation of retinal lesions in mice are well documented and applicable. The main drawback of using mice to study AMD is that the mouse retina has no macula. However, murine retinal degenerative diseases can still provide relevant information that will help our understanding of human AMD. Most of the retinal degeneration genes found first in mouse have been linked to a corresponding human retinal disease, and thus we know that identifying disease-related genes in mice is both relevant and important (Rakoczy et al., 2006). This section focuses on genetic-engineered mouse AMD models, which represent different spectrums of human AMD pathology and involve the molecules that we have discussed in the above text.

\subsection{Chemokine model}

5.2.1. $\mathrm{Ccl}^{-/-}$and $\mathrm{Ccr2}^{-/-}$murine models-CCR2 is a chemokine receptor on macrophages that binds MCP-1/CCL2 to mediate adhesion of inflammatory cells to the vasculature, as well as their subsequent extravasation into tissues. CCL2 or CCR2 deficiency leads to impaired accumulation of macrophages at sites of inflammation (Kuziel et al., 1997; Lu et al., 1998).

Indeed, a murine model of $C c l 2$ or $C c r 2$ deficiency leads to decreased accumulation of macrophages in the retina, as well as key features of AMD including drusen (Ambati et al., 2003). Ambati and colleagues demonstrated that the $C c l 2$ - and $C c r 2$ knockout mice $\left(C c l 2^{--}\right.$ and $C \mathrm{Cr}^{-/-}$) exhibit AMD-like drusen visible fundoscopically by 9 months of age. They also show histological and ultrastructural features of AMD including lipofuscin accumulation, thickening of Bruch membrane, and increased melanosomes in the RPE. Biochemical analysis revealed that A2E levels are similarly increased in these mice. Eventually, by 16-18 months of age, $\mathrm{C} C 2^{-1-}$ and $C \mathrm{Cr} 2^{-/-}$mice also develop geographic RPE atrophy and choroidal neovascularization.

In light of these findings, Ambati and colleagues hypothesized that impaired chemotaxis of macrophages to the retina impedes macrophage-mediated clearance of drusen components, leading to the generation of drusen deposits. They demonstrated that C5, IgG, and advanced glycosylation products, three components of drusen, normally upregulate Ccr2 expression in RPE cells and choroidal endothelial cells, presumably to attract macrophages. They further showed that macrophages are capable of adhering to IgG and C5 to promote their clearance. As expected, impaired macrophage recruitment in $C c l 2$ and $C c r 2$ deficient mice was associated with an accumulation of $\mathrm{C} 5, \mathrm{IgG}$, and other drusen constituents within the retina.

In short, the $\mathrm{Ccl} 2^{-/-}$and $\mathrm{Ccr} 2^{-/-}$murine models of AMD suggest a protective role for macrophages in AMD pathogenesis - clearance of deposits. The pathological features of this model include CNV. This is in stark contrast to a report by Tsutsumi et al. demonstrating that decreased macrophage influx after laser injury to $\mathrm{Ccl}^{-1-}$ mice is associated with reduced laserinduced CNV (Tsutsumi et al., 2003). These studies might be reconciled by the argument that laser-induced CNV, an acute injury, occurs by a different mechanism than CNV associated 
with age-related degenerative changes in the retina. Perhaps in the early stage of laser-induced CNV there is influx of inflammatory cells-perhaps M1 macrophages, if the macrophage polarization hypothesis described above holds true - that lead to cell injury and secretion of proangiogenic factors. In contrast, in the absence of such acute injury, M2 macrophages may play a housekeeping role, promoting clearance of deposits. Over time, failure of macrophage entry or function in the retina might lead to accumulation of deposits and drusen, which creates a nidus of low-grade inflammation, resulting in the tissue damage and eventually, CNV.

5.2.2. $\mathrm{C}_{3} 3 \mathrm{Cr}^{-/-}$murine model-Combadiere et al. recently reported a new $\mathrm{C} x 3 \mathrm{crl}^{-/-}$ murine model of AMD. $\mathrm{Cx} 3 \mathrm{crl}^{-/-}$mice demonstrated retinal degeneration and drusen-like deposits, which contained bloated accumulated microglia capable of phagocytosing outer segments of photoreceptor cells in 18 months and older mice. Moreover, $\mathrm{Cx}_{3} \mathrm{crl}^{-/-}$mice exhibited increased microglial accumulation after laser-injury, as well as worsened laserinduced CNV and retinal degeneration. Combadiere and colleagues hypothesized that $\mathrm{C} \times 3 \mathrm{crl}$ deficiency led to impaired microglial egress from the retina, facilitating their accumulation there, where they comprised drusen-like deposits and perhaps participated in retinal degeneration and CNV. The group pointed to the physical similarities between bloated microglial cells and drusen deposits, presence of organelles in drusen, and the fact that microglial cells can express some of the components commonly identified in drusen as evidence that drusen in AMD might involve, at least in part, accumulated microglial cells (Combadiere et al., 2007). The notion that microglia contribute to drusen-like deposits is further strengthened by another study demonstrating that increasing fundus autofluorescence seen in aging wild-type mice consists of perivascular and subretinal microglia, which might also contain lipofuscin granules (Xu et al., 2008). Moreover, as mentioned above, in vitro studies have demonstrated that activated microglia are capable of directly injuring photoreceptor cells (Roque et al., 1999). CX3CR1 positive cells in drusen and near CNV membranes are microglial cells in human AMD eyes (Combadiere et al., 2007). Taken together, these studies suggest a potential role for microglia accumulation in the inflammatory cascade associated with AMD.

5.2.3. $\mathrm{Ccl}^{-/-} / \mathrm{C} \times 3 \mathrm{cr}^{-/-}$murine model-Animal models based upon $C \mathrm{cl} 2$ and $C \times 3 \mathrm{crl}$ knockout have lent strength to this hypothesis and provided some insights into the potential inflammatory mechanisms underlying AMD pathogenesis. We investigated whether combining $C c l 2$ knockout, which has been shown to lead to AMD phenotype (described above), with $C x 3 \mathrm{crl}$ knockout might lead to a novel murine model of AMD with earlier onset and higher penetration. We found that $C c 2^{-1-} / \mathrm{Cx}_{3} \mathrm{crl}^{-/-}$mice exhibited, at an early age of 46 weeks, fundoscopically visible drusen-like lesions, as well as histological signs of AMD such as thickening of Bruch's membrane, drusen, local RPE hypopigmentation and degeneration, and photoreceptor disorganization and atrophy, as well as CNV in some mice. These mice also exhibited ultrastructural signs of AMD such as accumulation of lipofuscin granules, as well as increased the $N$-retinylidene $-N$-retinylethanolamine (A2E) accumulation on biochemical analysis (Chan et al., 2008; Tuo et al., 2007).

Given the central role of inflammatory processes in AMD, we recently characterized the immune status of the $C \mathrm{cl} 2^{-/-} / \mathrm{Cx} 3 \mathrm{cr} 1^{-/-}$mice. Compared to wild-type mice, $C \mathrm{cl} 2^{-/-}$I $\mathrm{Cx}_{3} \mathrm{Crl}^{-1-}$ mice exhibited increased complement C3 and CD46. Analysis of C3d expression by immunoreactivity revealed that this increase was especially notable in Bruch's membrane, drusen-like lesions, photoreceptors, RPE, and choroidal capillaries (Ross et al., 2008). These findings are consistent with findings in drusen of humans with AMD (Hageman et al., 2005), as well as the critical role in AMD of complement overactivity, which has been discussed above. Macrophage and microglial accumulation was also increased relative to wild-type in $\mathrm{Ccl}^{-/-} / \mathrm{Cx} 3 \mathrm{crl}^{-/-}$mice, as well as in $\mathrm{Cx} 3 \mathrm{crl}^{-/-}$mice, though to a lesser degree (Ross et al., 2008). Given prior reports of increased anti-retinal antibodies in patients with AMD (Cherepanoff et al., 2006; Joachim et al., 2007; Patel et al., 2005), we also investigated whether 
our mouse model possesses such antibodies. Incubation of normal retinal sections with serum from $\mathrm{Ccl} 2^{-/-} / \mathrm{Cx}_{3} \mathrm{crl}^{-/-}$also demonstrated the presence of anti-retinal antibodies in the mouse model. In contrast, minimal anti-retinal auto-antibody effect was noted in wild-type mice (Ross et al., 2008). These findings highlight that the $C \mathrm{cl} 2^{-1-} / C x 3 \mathrm{crl}^{-1-}$ murine model of AMD is a robust one with several immunological features also documented in human AMD and supported by studies in other in vivo models of AMD. They also strengthen the argument for a critical inflammatory component to AMD pathogenesis.

\section{3. $\mathrm{Cfh}^{-/-}$murine model}

As discussed above, $\mathrm{CFH}$ polymorphisms are associated with susceptibility to AMD in more than half of affected individuals. To further investigate the role of CFH in AMD pathogenesis, Coffey et al. reported visual and retinal findings in mice deficient in $c f h$. At age 2 years, $c \mathrm{fh}^{-/-}$mice exhibited significantly reduced visual acuity and rod response amplitudes on electroretinography as compared with age-matched control mice (Coffey et al., 2007). These mice also demonstrated increased autofluorescence, accumulation of $\mathrm{C} 3$, and disorganization of photoreceptor outer segments in the retina, as well as thinning of Bruch's membrane and increased RPE organelles. Funduscopic examination and vasculature, however, appears normal in the $c f h^{-/-}$mice. Coffey et al. hypothesized that a major difference between the $c f h$ polymorphisms associated with human AMD and homozygous deficiency of $\mathrm{CFH}$ is that in the latter, plasma C3 levels are markedly reduced, while in the former, they are normal. Secondary C3 deficiency may critically influence the ocular phenotypes in the $c f h^{-/-}$mice.

\subsection{ApoE-based murine model}

As discussed above, prior studies have suggested a probable association between ApoE polymorphisms and AMD. To investigate the role of ApoE in AMD pathogenesis, Malek and colleagues generated mice transgenic for each of the human ApoE allelesd-E2, E3, and E4 (Malek et al., 2005). They found that diet withstanding, ApoE status alone affected retinal changes during aging only minimally. In contrast, both ApoE2 and ApoE4 transgenic mice developed extensive retinal, RPE, and choroidal degeneration after a high fat cholesterol rich (HF-CR) diet. Aged ApoE4 mice on this diet exhibited several features of human AMD, including drusen, thickening of Bruch's membrane, geographic RPE atrophy, and CNV. This model is in fact an improvement upon the prior ApoE-Leiden plus high fat diet model, which demonstrated only basal laminar deposits in Bruch's membrane. Moreover, CNV in aged ApoE4 mice on the HF-CR diet contained amyloid $\beta$ deposits, as well as VEGF and other factors also seen in human AMD and CNV. Malek and colleagues hypothesized that these effects might be due to the impaired cholesterol clearance and anti-oxidative properties of ApoE4, compared to ApoE3, which have been demonstrated previously. The findings from this study are somewhat contrary to several prior epidemiological studies that demonstrated a protective, rather than risk-conferring, role for the ApoE4 variant. Malek and colleagues addressed this concern by citing potential differences between human and mouse physiology, the homozygosity of their model versus the relative abundance of heterozygotes in the human epidemiological studies, as well as the important additional factor of diet included in the mouse model.

Most importantly, the ApoE-based murine model of AMD highlights the potential role for cholesterol metabolism in AMD pathogenesis and further emphasized the need to clarify the role of $A p o E$ variants in human AMD. The role of cholesterol metabolism in AMD has been further supported by recent studies demonstrating that, in contrast to wild-type eyes, mice expressing ApoE2 exhibited signs of lipid accumulation in the RPE and Bruch's membrane (Lee et al., 2007). This effect was even more pronounced in ApoE2 transgenic mice fed with a high fat diet. Moreover, the eyes of ApoE2 transgenic mice also expressed higher levels of 
the proangiogenic factor VEGF but lower levels of anti-angiogenic factor pigment epithelium derived factor (PEDF).

\section{5. $\mathrm{Abcr}^{-/-}$murine model}

As discussed above, polymorphisms in the $A B C A 4$ gene might contribute to AMD pathogenesis, and recent studies in an abcr (abca4) knockout mouse $\left(\mathrm{Abcr}^{-/-}\right)$highlight potential mechanisms underlying maculopathy in patients with putative risk-conferring $A B C A 4$ polymorphisms and perhaps even AMD in general. $\mathrm{Abcr}^{-1-}$ mice demonstrate decreased dark adaptation, increased all-trans-retinaldehyde after light exposure, increased phosphatidylethanolamine (PE) in outer segments, accumulation of $N$-retinylidenephosphatidylethanolamine, the conjugate of all-trans retinaldehyde and PE in photoreceptors, and deposition of A2E fluorophore, a major component of lipofuscin, in the RPE (Weng et al., 1999). Based on these findings, Weng et al. hypothesized that rim protein encoded by $A B C A 4$ acts as a flippase for $N$-retinylidene-phosphatidylethanolamine ( $N$-retinylidene-PE). By promoting the transfer of all-trans retinal-containing $N$-retinylidene-PE from the disk interior to the cytoplasmic surface, rim protein might facilitate the recovery of rod sensitivity after light exposure, which usually involves rhodopsin regeneration accompanied by disappearance of all-trans retinaldehyde. Moreover, impaired flippase activity explains the observed accumulation in the RPE of $\mathrm{abcr}^{-1-}$ mice of protonated $\mathrm{N}$-retinylidene-PE and its byproduct A2E, the major fluorophore of pathological lipofuscin in retinal degenerative diseases. These processes might therefore contribute to impaired RPE function and subsequent RPE and photoreceptor degeneration (Weng et al., 1999). In addition to photoreceptor degeneration and lipofuscin accumulation, this model also demonstrates decreased recovery of rod cell sensitivity after light exposure (Midena et al., 1997; Weng et al., 1999). Ultrastructural analysis revealed abnormal basal RPE with small irregular dense bodies in both $\mathrm{abcr}^{-1-}$ and $\mathrm{abcr}^{+/-}$mice, but no drusen formation (Mata et al., 2001).

\section{Summary}

AMD is a debilitating disease of the retina, which manifests clinically with loss of central vision and pathologically with the accumulation of drusen, RPE degeneration, photoreceptor atrophy, and in some cases, with CNV. While several risk factors, including age, race, smoking, and diet have been linked to AMD, the etiology and pathogenesis of the disease remain largely unclear. Treatment options for the condition are similarly limited. As the prevalence of this already widespread disease soars in coming years with the general aging of the population, there will be a concomitant need for novel preventative and therapeutic strategies. The identification of the optimal and appropriate therapies will depend, in turn, upon a thorough appreciation of the molecular underpinnings of AMD development and progression.

Recent studies on the molecular pathology of AMD suggest important roles for oxidative stress, inflammation, lipid metabolism, and angiogenesis. The retina in general, and macula in particular are highly susceptible to oxidative stress given the elevated oxygen tension, high metabolic activity, exposure to photoradiation, presence of photosensitizers, and oxidizing processes of photoreceptor phagocytosis. The role of oxidative stress is further strengthened by epidemiological studies demonstrating increased risk with smoking, a potent oxidizing stress, and decreased risk with diets rich in antioxidants such as lutein/zeaxanthin.

Pathology of AMD lesions classically demonstrates signs of persistent chronic inflammatory damage, including not only mild infiltration of macrophages and accumulation of microglia, but also presence of inflammatory components such as complement factors and proinflammatory cytokines/chemokines in the drusen and AMD lesions. Recent findings demonstrating a genetic link between the complement system members including $\mathrm{C} 1, \mathrm{C} 2, \mathrm{C} 3$, $\mathrm{C} 7, \mathrm{BF}$, and especially, $\mathrm{CFH}$ provide a compelling argument for complement over-activation 
in AMD pathogenesis. $\mathrm{CFH}$ polymorphisms have been linked to a pro-inflammatory state, including increased CRP and decreased complement inhibitory effect. Compared to the scenario with complement, the precise role of macrophages and microglia in AMD pathogenesis-i.e. deciphering whether they are protective, harmful, or both—is less clear.

The association of ApoE alleles with AMD, as well as recent ApoE-based animal models of AMD, suggest a potential role for aberrant cholesterol and lipid trafficking and metabolism in AMD pathogenesis. Even more compelling, however, is the role of VEGF in AMD. VEGF is a key angiogenic factor in the development of $\mathrm{CNV}$ in late stage $\mathrm{AMD}$, and recent studies suggest that polymorphisms in the $V E G F$ gene might contribute to risk of AMD and to efficacy of anti-VEGF therapy. Indeed, much like the elucidation of VEGF in CNV membranes of AMD patients led eventually to the development of anti-VEGF agents for wet AMD, the knowledge gleaned from the emerging field of molecular epidemiology and pathology of AMD will be a critical antecedent to the quest for novel AMD therapeutics.

\section{Future direction}

Though AMD research has made great advances in recent years, our understanding of its pathogenesis remains largely incomplete. Given the context specificity of many critical biological processes and the fact that most common diseases including AMD are thought to be the outcome of a complex interaction between many genetic loci and the environment, it follows that there are obvious advantages to studying gene expression in cells and tissues that represent the in vivo state. For example, in a recent study on the expression of 23,720 transcripts from trials on blood samples $(n=1002)$ or adipose tissue $(n=673)$, findings from over $50 \%$ of trials in adipose samples correlated to those from clinical trials related to obesity, compared to less than $10 \%$ in trials on blood samples (Emilsson et al., 2008). Similarly, findings from molecular pathology are likely to contribute to our understanding of the mechanisms underlying AMD, especially with regard to the role of various molecular factors, several of which are genetically determined. Further research is needed to delineate the entire process of AMD development and to identify unknown molecular factors mediating AMD pathogenesis. High-throughput techniques in molecular biology, such as microarray analysis and epigenotyping for gene expression profiling, may help achieve these goals.

The identification of SNPs that are associated with variation in gene expression on the retina and in the eye provides a level of functional support making these SNPs ideal starting points for the identification of molecular determinants of complex traits including diseases development and drug response. On the other hand, a refined phenotypic morphological classification may be helpful to identify prognostic determinants for AMD, as well as develop effective therapies. Indeed, the discovery of novel therapeutic strategies that produce a clinical response while minimizing adverse events depends largely upon the identification of molecules specific to the pathological process of AMD. Moreover, AMD appears to be a highly multifactorial disease likely caused by individual-specific combinations of etiological and risk factors that affect not only the disease itself but also its response to various treatment modalities. For example, AMD patients with risk-conferring $C F H$ SNP showed less response to antioxidant and zinc therapy as compared to those without the SNP (Klein et al., 2008a). Thus, future studies on the molecular pathology of AMD might help to identify specific molecular signatures of AMD and ultimately help to improve quality of life for AMD patients.

\section{Acknowledgments}

We would like to thank Dr. Robert B. Nussenblatt for his critical review. The support for this study was provided by the NEI Intramural Research Program. 


\section{References}

Allikmets R. A photoreceptor cell-specific ATP-binding transporter gene (ABCR) is mutated in recessive Stargardt macular dystrophy. Nat. Genet 1997;17:122. [PubMed: 9288113]

Allikmets R, Shroyer NF, Singh N, Seddon JM, Lewis RA, Bernstein PS, Peiffer A, Zabriskie NA, Li Y, Hutchinson A, Dean M, Lupski JR, Leppert M. Mutation of the Stargardt disease gene (ABCR) in age-related macular degeneration. Science 1997;277:1805-1807. [PubMed: 9295268]

Alsenz J, Schulz TF, Lambris JD, Sim RB, Dierich MP. Structural and functional analysis of the complement component factor $\mathrm{H}$ with the use of different enzymes and monoclonal antibodies to factor H. Biochem. J 1985;232:841-850. [PubMed: 2936333]

Ambati J, Anand A, Fernandez S, Sakurai E, Lynn BC, Kuziel WA, Rollins BJ, Ambati BK. An animal model of age-related macular degeneration in senescent Ccl-2- or Ccr-2-deficient mice. Nat. Med 2003;9:1390-1397. [PubMed: 14566334]

Anderson DH, Talaga KC, Rivest AJ, Barron E, Hageman GS, Johnson LV. Characterization of beta amyloid assemblies in drusen: the deposits associated with aging and age-related macular degeneration. Exp. Eye Res 2004;78:243-256. [PubMed: 14729357]

Apte RS, Richter J, Herndon J, Ferguson TA. Macrophages inhibit neovascularization in a murine model of age-related macular degeneration. PLoS Med 2006;3:e310. [PubMed: 16903779]

Arbour NC, Lorenz E, Schutte BC, Zabner J, Kline JN, Jones M, Frees K, Watt JL, Schwartz DA. TLR4 mutations are associated with endotoxin hyporesponsiveness in humans. Nat. Genet 2000;25:187-191. [PubMed: 10835634]

AREDS (Age-Related Eye Disease Study Research Group). A randomized, placebo-controlled, clinical trial of high-dose supplementation with vitamins $\mathrm{C}$ and $\mathrm{E}$, beta carotene, and zinc for age-related macular degeneration and vision loss: AREDS report no. 8. Arch. Ophthalmol 2001;119:1417-1436. [PubMed: 11594942]

Azarian SM, Travis GH. The photoreceptor rim protein is an ABC transporter encoded by the gene for recessive Stargardt's disease (ABCR). FEBS Lett 1997;409:247-252. [PubMed: 9202155]

Baird PN, Richardson AJ, Robman LD, Dimitrov PN, Tikellis G, McCarty CA, Guymer RH. Apolipoprotein (APOE) gene is associated with progression of age-related macular degeneration (AMD). Hum. Mutat 2006;27:337-342. [PubMed: 16453339]

Baird PN, Robman LD, Richardson AJ, Dimitrov PN, Tikellis G, McCarty CA, Guymer RH. Geneenvironment interaction in progression of AMD: the $\mathrm{CFH}$ gene, smoking and exposure to chronic infection. Hum. Mol. Genet 2008;17:1299-1305. [PubMed: 18203751]

Ballinger SW, Van Houten B, Jin GF, Conklin CA, Godley BF. Hydrogen peroxide causes significant mitochondrial DNA damage in human RPE cells. Exp. Eye Res 1999;68:765-772. [PubMed: 10375440]

Barreau C, Paillard L, Osborne HB. AU-rich elements and associated factors: are there unifying principles? Nucleic Acids Res 2005;33:7138-7150. [PubMed: 16391004]

Barron MJ, Johnson MA, Andrews RM, Clarke MP, Griffiths PG, Bristow E, He LP, Durham S, Turnbull DM. Mitochondrial abnormalities in ageing macular photoreceptors. Invest. Ophthalmol. Vis. Sci 2001;42:3016-3022. [PubMed: 11687550]

Bojanowski CM, Tuo J, Chew EY, Csaky KG, Chan CC. Analysis of Hemicentin-1, hOgg1, and Eselectin single nucleotide polymorphisms in age-related macular degeneration. Trans. Am. Ophthalmol. Soc 2005;103:44-45. 37-44.discussion

Bojanowski CM, Shen D, Chew EY, Ning B, Csaky KG, Green WR, Chan CC, Tuo J. An apolipoprotein E variant may protect against age-related macular degeneration through cytokine regulation. Environ. Mol. Mutagen 2006;47:594-602. [PubMed: 16823865]

Bora N, Jha P, Bora P. The role of complement in ocular pathology. Semin. Immunopathol 2008;30:8595. [PubMed: 18299835]

Brancato R, Introini U, Pierro L, Setaccioli M, Forti M, Bolognesi G, Tremolada G. Optical coherence tomography (OCT) angiomatous prolifieration (RAP) in retinal. Eur. J. Ophthalmol 2002;12:467472. [PubMed: 12510715] 
Brantley MA Jr, Edelstein SL, King JM, Plotzke MR, Apte RS, Kymes SM, Shiels A. Association of complement factor $\mathrm{H}$ and LOC387715 genotypes with response of exudative age-related macular degeneration to photodynamic therapy. Eye 2008. 2008 February 22; [Epub ahead of print]

Bressler NM, Bressler SB, Congdon NG, Ferris FL 3rd, Friedman DS, Klein R, Lindblad AS, Milton RC, Seddon JM. Potential public health impact of Age-Related Eye Disease Study results: AREDS report no. 11. Arch. Ophthalmol 2003;121:1621-1624. [PubMed: 14609922]

Cameron DJ, Yang Z, Gibbs D, Chen H, Kaminoh Y, Jorgensen A, Zeng J, Luo L, Brinton E, Brinton G, Brand JM, Bernstein PS, Zabriskie NA, Tang S, Constantine R, Tong Z, Zhang K. HTRA1 variant confers similar risks to geographic atrophy and neovascular age-related macular degeneration. Cell Cycle 2007;6:1122-1125. [PubMed: 17426452]

Chan CC, Tuo J, Bojanowski CM, Csaky KG, Green WR. Detection of CX3CR1 single nucleotide polymorphism and expression on archived eyes with age-related macular degeneration. Histol. Histopathol 2005;20:857-863. [PubMed: 15944936]

Chan CC, Shen D, Zhou M, Ross RJ, Ding X, Zhang K, Green WR, Tuo J. Human HtrA1 in the archived eyes with age-related macular degeneration. Trans. Am. Ophthalmol. Soc 2007;105:97-98. 9297.discussion

Chan CC, Ross RJ, Shen D, Ding X, Majumdar Z, Bojanowski CM, Zhou M, Salem N Jr, Bonner R, Tuo J. Ccl2/Cx3cr1-deficient mice: an animal model for age-related macular degeneration. Ophthalmic Res 2008;40:124-128. [PubMed: 18421225]

Chen LJ, Liu DT, Tam PO, Chan WM, Liu K, Chong KK, Lam DS, Pang CP. Association of complement factor $\mathrm{H}$ polymorphisms with exudative age-related macular degeneration. Mol. Vis 2006;12:15361542. [PubMed: 17167412]

Chen H, Liu B, Lukas TJ, Neufeld AH. The aged retinal pigment epithelium/choroid: a potential substratum for the pathogenesis of age-related macular degeneration. PLoS ONE 2008;3:e2339. [PubMed: 18523633]

Cherepanoff S, Mitchell P, Wang JJ, Gillies MC. Retinal autoantibody profile in early age-related macular degeneration: preliminary findings from the Blue Mountains Eye Study. Clin. Exp. Ophthalmol 2006;34:590-595.

Cho E, Hung S, Willett WC, Spiegelman D, Rimm EB, Seddon JM, Colditz GA, Hankinson SE. Prospective study of dietary fat and the risk of age-related macular degeneration. Am. J. Clin. Nutr 2001;73:209-218. [PubMed: 11157315]

Churchill AJ, Carter JG, Lovell HC, Ramsden C, Turner SJ, Yeung A, Escardo J, Atan D. VEGF polymorphisms are associated with neovascular age-related macular degeneration. Hum. Mol. Genet 2006;15:2955-2961. [PubMed: 16940309]

Clausen T, Southan C, Ehrmann M. The HtrA family of proteases: implications for protein composition and cell fate. Mol. Cell 2002;10:443-455. [PubMed: 12408815]

Coffey PJ, Gias C, McDermott CJ, Lundh P, Pickering MC, Sethi C, Bird A, Fitzke FW, Maass A, Chen LL, Holder GE, Luthert PJ, Salt TE, Moss SE, Greenwood J. Complement factor H deficiency in aged mice causes retinal abnormalities and visual dysfunction. Proc. Natl. Acad. Sci. U.S.A 2007;104:16651-16656. [PubMed: 17921253]

Coleman HR, Chan CC, Ferris FL III, Chew EY. Age-related macular degeneration. Lancet 2008;372:1835-1845. [PubMed: 19027484]

Combadiere C, Gao J, Tiffany HL, Murphy PM. Gene cloning, RNA distribution, and functional expression of mCX3CR1, a mouse chemotactic receptor for the CX3C chemokine fractalkine. Biochem. Biophys. Res. Commun 1998;253:728-732. [PubMed: 9918795]

Combadiere C, Feumi C, Raoul W, Keller N, Rodero M, Pezard A, Lavalette S, Houssier M, Jonet L, Picard E, Debre P, Sirinyan M, Deterre P, Ferroukhi T, Cohen SY, Chauvaud D, Jeanny JC, Chemtob $\mathrm{S}$, Behar-Cohen F, Sennlaub F. CX3CR1-dependent subretinal microglia cell accumulation is associated with cardinal features of age-related macular degeneration. J. Clin. Invest 2007;117:29202928. [PubMed: 17909628]

Conley YP, Jakobsdottir J, Mah T, Weeks DE, Klein R, Kuller L, Ferrell RE, Gorin MB. CFH, ELOVL4, PLEKHA1 and LOC387715 genes and susceptibility to age-related maculopathy: AREDS and CHS cohorts and meta-analyses. Hum. Mol. Genet 2006;15:3206-3218. [PubMed: 17000705] 
Crabb JW, Miyagi M, Gu X, Shadrach K, West KA, Sakaguchi H, Kamei M, Hasan A, Yan L, Rayborn ME, Salomon RG, Hollyfield JG. Drusen proteome analysis: an approach to the etiology of agerelated macular degeneration. Proc. Natl. Acad. Sci. U.S.A 2002;99:14682-14687. [PubMed: 12391305]

Csaky K, Baffi J, Chan CC, Byrnes GA. Clinicopathologic correlation of progressive fibrovascular proliferation associated with occult choroidal neovascularization in age-related macular degeneration. Arch. Ophthalmol 2004;122:650-652. [PubMed: 15078686]

Curcio CA, Millican CL. Basal linear deposit and large drusen are specific for early age-related maculopathy. Arch. Ophthalmol 1999;117:329-339. [PubMed: 10088810]

Dastgheib K, Green WR. Granulomatous reaction to Bruch's membrane in age-related macular degeneration. Arch. Ophthalmol 1994;112:813-818. [PubMed: 7516148]

de Jong PT. Age-related macular degeneration. N. Engl. J. Med 2006;355:1474-1485. [PubMed: 17021323]

de Jong PT, Bockhoorn SS, Vingerling JR, Uitterlinden AG, Hoffman A. Polymorphisms in the Vascular Endothelial Growth Factor Gene and Risk of Aging Macula Disorder: The Rotterdam Study. Invest. Ophthalmol. Vis. Sci 2007;48:E-2119.

De La Paz MA, Guy VK, Abou-Donia S, Heinis R, Bracken B, Vance JM, Gilbert JR, Gass JD, Haines JL, Pericak-Vance MA. Analysis of the Stargardt disease gene (ABCR) in age-related macular degeneration. Ophthalmology 1999;106:1531-1536. [PubMed: 10442900]

Deangelis MM, Ji F, Adams S, Morrison MA, Harring AJ, Sweeney MO, Capone A Jr, Miller JW, Dryja TP, Ott J, Kim IK. Alleles in the HtrA serine peptidase 1 gene alter the risk of neovascular age-related macular degeneration. Ophthalmology 2008;115:1209-1215. [PubMed: 18164066] 7

Decanini A, Nordgaard CL, Feng X, Ferrington DA, Olsen TW. Changes in select redox proteins of the retinal pigment epithelium in age-related macular degeneration. Am. J. Ophthalmol 2007;143:607615. [PubMed: 17280640]

Despriet DD, Bergen AA, Merriam JE, Zernant J, Barile GR, Smith RT, Barbazetto IA, van Soest S, Bakker A, de Jong PT, Allikmets R, Klaver CC. Comprehensive analysis of the candidate genes CCL2, CCR2, and TLR4 in age-related macular degeneration. Invest. Ophthalmol. Vis. Sci 2008;49:364-371. [PubMed: 18172114]

Dewan A, Liu M, Hartman S, Zhang SS, Liu DT, Zhao C, Tam PO, Chan WM, Lam DS, Snyder M, Barnstable C, Pang CP, Hoh J. HTRA1 promoter polymorphism in wet age-related macular degeneration. Science 2006;314:989-992. [PubMed: 17053108]

Dinu V, Miller PL, Zhao H. Evidence for association between multiple complement pathway genes and AMD. Genet. Epidemiol 2007;31:224-237. [PubMed: 17266113]

Donati MC, Carifi G, Virgili G, Menchini U. Retinal angiomatous proliferation: association with clinical and angiographic features. Ophthalmologica 2006;220:31-36. [PubMed: 16374046]

Edwards AO, Ritter R 3rd, Abel KJ, Manning A, Panhuysen C, Farrer LA. Complement factor H polymorphism and age-related macular degeneration. Science 2005;308:421-424. [PubMed: 15761121]

Edwards AO, Chen D, Fridley BL, James KM, Wu Y, Abecasis G, Swaroop A, Othman M, Branham K, Iyengar SK, Sivakumaran TA, Klein R, Klein BE, Tosakulwong N. Toll-like receptor polymorphisms and age-related macular degeneration. Invest. Ophthalmol. Vis. Sci 2008;49:1652-1659. [PubMed: 18385087]

Emilsson V, Thorleifsson G, Zhang B, Leonardson AS, Zink F, Zhu J, Carlson S, Helgason A, Walters GB, Gunnarsdottir S, Mouy M, Steinthorsdottir V, Eiriksdottir GH, Bjornsdottir G, Reynisdottir I, Gudbjartsson D, Helgadottir A, Jonasdottir A, Jonasdottir A, Styrkarsdottir U, Gretarsdottir S, Magnusson KP, Stefansson H, Fossdal R, Kristjansson K, Gislason HG, Stefansson T, Leifsson BG, Thorsteinsdottir U, Lamb JR, Gulcher JR, Reitman ML, Kong A, Schadt EE, Stefansson K. Genetics of gene expression and its effect on disease. Nature 2008;452:423-428. [PubMed: 18344981]

Ennis S, Jomary C, Mullins R, Cree A, Chen X, Macleod A, Jones S, Collins A, Stone E, Lotery A. Association between the SERPING1 gene and age-related macular degeneration: a two-stage casecontrol study. Lancet 2008. 2008 October 6; [Epub ahead of print] 
Espinosa-Heidmann DG, Suner IJ, Hernandez EP, Monroy D, Csaky KG, Cousins SW. Macrophage depletion diminishes lesion size and severity in experimental choroidal neovascularization. Invest. Ophthalmol. Vis. Sci 2003;44:3586-3592. [PubMed: 12882811]

Fagerness JA, Maller JB, Neale BM, Reynolds RC, Daly MJ, Seddon JM, et al. Variation near complement factor I is associated with risk of advanced AMD. Eur. J. Hum. Genet. 2008. 2008 August 6; [Epub ahead of print]

Feher J, Kovacs I, Artico M, Cavallotti C, Papale A, Balacco Gabrieli C. Mitochondrial alterations of retinal pigment epithelium in age-related macular degeneration. Neurobiol. Aging 2006;27:983-993. [PubMed: 15979212]

Ferrara N, Gerber HP, LeCouter J. The biology of VEGF and its receptors. Nat. Med 2003;9:669-676. [PubMed: 12778165]

Ferrara N, Damico L, Shams N, Lowman H, Kim R. Development of ranibizumab, an anti-vascular endothelial growth factor antigen binding fragment, as therapy for neovascular age-related macular degeneration. Retina 2006;26:859-870. [PubMed: 17031284]

Finn JE, Mathieson PW. Molecular analysis of C3 allotypes in patients with nephritic factor. Clin. Exp. Immunol 1993;91:410-414. [PubMed: 8443964]

Fisher SA, Abecasis GR, Yashar BM, Zareparsi S, Swaroop A, Iyengar SK, Klein BE, Klein R, Lee KE, Majewski J, Schultz DW, Klein ML, Seddon JM, Santangelo SL, Weeks DE, Conley YP, Mah TS, Schmidt S, Haines JL, Pericak-Vance MA, Gorin MB, Schulz HL, Pardi F, Lewis CM, Weber BH. Meta-analysis of genome scans of age-related macular degeneration. Hum. Mol. Genet 2005;14:2257-2264. [PubMed: 15987700]

Fong AM, Robinson LA, Steeber DA, Tedder TF, Yoshie O, Imai T, Patel DD. Fractalkine and CX3CR1 mediate a novel mechanism of leukocyte capture, firm adhesion, and activation under physiologic flow. J. Exp. Med 1998;188:1413-1419. [PubMed: 9782118]

Foxman EF, Zhang M, Hurst SD, Muchamuel T, Shen D, Wawrousek EF, Chan CC, Gery I. Inflammatory mediators in uveitis: differential induction of cytokines and chemokines in Th1- versus Th2-mediated ocular inflammation. J. Immunol 2002;168:2483-2492. [PubMed: 11859142]

Frank RN, Amin RH, Puklin JE. Antioxidant enzymes in the macular retinal pigment epithelium of eyes with neovascular age-related macular degeneration. Am. J. Ophthalmol 1999;127:694-709. [PubMed: 10372880]

Friedman DS, O'Colmain BJ, Munoz B, Tomany SC, McCarty C, de Jong PT, Nemesure B, Mitchell P, Kempen J. Prevalence of age-related macular degeneration in the United States. Arch. Ophthalmol 2004;122:564-572. [PubMed: 15078675]

Fritsche LG, Loenhardt T, Janssen A, Fisher SA, Rivera A, Keilhauer CN, Weber BH. Age-related macular degeneration is associated with an unstable ARMS2 (LOC387715) mRNA. Nat. Genet 2008;40:892-896. [PubMed: 18511946]

Garneau NL, Wilusz J, Wilusz CJ. The highways and byways of mRNA decay. Nat. Rev. Mol. Cell Biol 2007;8:113-126. [PubMed: 17245413]

Gehrs KM, Anderson DH, Johnson LV, Hageman GS. Age-related macular degeneration-emerging pathogenetic and therapeutic concepts. Ann. Med 2006;38:450-471. [PubMed: 17101537]

Ghazi NG. Retinal angiomatous proliferation in age-related macular degeneration. Retina 2002;22:509511. [PubMed: 12172126] author reply 512

Godley BF, Shamsi FA, Liang FQ, Jarrett SG, Davies S, Boulton M. Blue light induces mitochondrial DNA damage and free radical production in epithelial cells. J. Biol. Chem 2005;280:21061-21066. [PubMed: 15797866]

Gold B, Merriam JE, Zernant J, Hancox LS, Taiber AJ, Gehrs K, Cramer K, Neel J, Bergeron J, Barile GR, Smith RT, Hageman GS, Dean M, Allikmets R. Variation in factor B (BF) and complement component $2(\mathrm{C} 2)$ genes is associated with age-related macular degeneration. Nat. Genet 2006;38:458-462. [PubMed: 16518403]

Goverdhan SV, Ennis S, Hannan SR, Madhusudhana KC, Cree AJ, Luff AJ, Lotery AJ. Interleukin-8 promoter polymorphism $-251 \mathrm{~A} / \mathrm{T}$ is a risk factor for age-related macular degeneration. Br. J. Ophthalmol 2008;92:537-540. [PubMed: 18310311]

Gragoudas ES, Adamis AP, Cunningham ET Jr, Feinsod M, Guyer DR. Pegaptanib for neovascular agerelated macular degeneration. N. Engl. J. Med 2004;351:2805-2816. [PubMed: 15625332] 
Grau S, Richards PJ, Kerr B, Hughes C, Caterson B, Williams AS, Junker U, Jones SA, Clausen T, Ehrmann M. The role of human HtrA1 in arthritic disease. J. Biol. Chem 2006;281:6124-6129. [PubMed: 16377621]

Green, WR. Retina: growth and aging. In: Bilyk; Folberg; Font; Green; Howes; Jakkobiec; McLean; Rao, editors. Ophthalmic Pathology. Vol. fourth rev, ed.. Vol. Vol. 2.. Saunders; 1996. p. 676-681.

Green WR. Histopathology of age-related macular degeneration. Mol. Vis 1999;5:27. [PubMed: 10562651]

Green WR, Enger C. Age-related macular degeneration histopathologic studies. The 1992 Lorenz E. Zimmerman Lecture. Ophthalmology 1993;100:1519-1535. [PubMed: 7692366]

Grossniklaus HE, Ling JX, Wallace TM, Dithmar S, Lawson DH, Cohen C, Elner VM, Elner SG, Sternberg P Jr. Macrophage and retinal pigment epithelium expression of angiogenic cytokines in choroidal neovascularization. Mol. Vis 2002;8:119-126. [PubMed: 11979237]

Gupta N, Brown KE, Milam AH. Activated microglia in human retinitis pigmentosa, late-onset retinal degeneration, and age-related macular degeneration. Exp. Eye Res 2003;76:463-471. [PubMed: 12634111]

Hageman GS, Mullins RF, Russell SR, Johnson LV, Anderson DH. Vitronectin is a constituent of ocular drusen and the vitronectin gene is expressed in human retinal pigmented epithelial cells. FASEB J 1999;13:477-484. [PubMed: 10064614]

Hageman GS, Luthert PJ, Victor Chong NH, Johnson LV, Anderson DH, Mullins RF. An integrated hypothesis that considers drusen as biomarkers of immune-mediated processes at the RPE-Bruch's membrane interface in aging and age-related macular degeneration. Prog. Retin. Eye Res 2001;20:705-732. [PubMed: 11587915]

Hageman GS, Anderson DH, Johnson LV, Hancox LS, Taiber AJ, Hardisty LI, Hageman JL, Stockman HA, Borchardt JD, Gehrs KM, Smith RJ, Silvestri G, Russell SR, Klaver CC, Barbazetto I, Chang S, Yannuzzi LA, Barile GR, Merriam JC, Smith RT, Olsh AK, Bergeron J, Zernant J, Merriam JE, Gold B, Dean M, Allikmets R. A common haplotype in the complement regulatory gene factor $\mathrm{H}$ (HF1/CFH) predisposes individuals to age-related macular degeneration. Proc. Natl. Acad. Sci. U.S.A 2005;102:7227-7232. [PubMed: 15870199]

Haines JL, Hauser MA, Schmidt S, Scott WK, Olson LM, Gallins P, Spencer KL, Kwan SY, Noureddine M, Gilbert JR, Schnetz-Boutaud N, Agarwal A, Postel EA, Pericak-Vance MA. Complement factor $H$ variant increases the risk of age-related macular degeneration. Science 2005;308:419-421. [PubMed: 15761120]

Haines JL, Schnetz-Boutaud N, Schmidt S, Scott WK, Agarwal A, Postel EA, Olson L, Kenealy SJ, Hauser M, Gilbert JR, Pericak-Vance MA. Functional candidate genes in age-related macular degeneration: significant association with VEGF, VLDLR, and LRP6. Invest. Ophthalmol. Vis. Sci 2006;47:329-335. [PubMed: 16384981]

Hakobyan S, Harris CL, van den Berg CW, Fernandez-Alonso MC, Goicoechea de Jorge E, Rodriguez de Cordoba S, Rivas G, Mangione P, Pepys MB, Morgan BP. Complement factor H binds to denatured rather than to native pentameric C-reactive protein. J. Biol. Chem 2008;283:30451-30460. [PubMed: 18786923]

Howes KA, Liu Y, Dunaief JL, Milam A, Frederick JM, Marks A, Baehr W. Receptor for advanced glycation end products and age-related macular degeneration. Invest. Ophthalmol. Vis. Sci 2004;45:3713-3720. [PubMed: 15452081]

Hunter MA, Dunbar MT, Rosenfeld PJ. Retinal angiomatous proliferation: clinical characteristics and treatment options. Optometry 2004;75:577-588. [PubMed: 15481226]

Hutchison J, Tay W. Symmetrical central choroidoretinal disease occurring in senile persons. R. Lond. Ophthal. Hosp. Rep 1875;8:231-244.

Ishida BY, Bailey KR, Duncan KG, Chalkley RJ, Burlingame AL, Kane JP, Schwartz DM. Regulated expression of apolipoprotein E by human retinal pigment epithelial cells. J. Lipid Res 2004;45:263271. [PubMed: 14594998]

Jager RD, Mieler WF, Miller JW. Age-related macular degeneration. N. Engl. J. Med 2008;358:26062617. [PubMed: 18550876] 
Jakobsdottir J, Conley YP, Weeks DE, Mah TS, Ferrell RE, Gorin MB. Susceptibility genes for agerelated maculopathy on chromosome 10q26. Am. J. Hum. Genet 2005;77:389-407. [PubMed: 16080115]

Joachim SC, Bruns K, Lackner KJ, Pfeiffer N, Grus FH. Analysis of IgG antibody patterns against retinal antigens and antibodies to alpha-crystallin, GFAP, and alpha-enolase in sera of patients with "wet" age-related macular degeneration. Graefes Arch. Clin. Exp. Ophthalmol 2007;245:619-626. [PubMed: 17058093]

Johnson LV, Ozaki S, Staples MK, Erickson PA, Anderson DH. A potential role for immune complex pathogenesis in drusen formation. Exp. Eye Res 2000;70:441-449. [PubMed: 10865992]

Johnson LV, Leitner WP, Staples MK, Anderson DH. Complement activation and inflammatory processes in Drusen formation and age related macular degeneration. Exp. Eye Res 2001;73:887896. [PubMed: 11846519]

Johnson LV, Leitner WP, Rivest AJ, Staples MK, Radeke MJ, Anderson DH. The Alzheimer's A betapeptide is deposited at sites of complement activation in pathologic deposits associated with aging and age-related macular degeneration. Proc. Natl. Acad. Sci. U.S.A 2002;99:11830-11835. [PubMed: 12189211]

Johnson PT, Betts KE, Radeke MJ, Hageman GS, Anderson DH, Johnson LV. Individuals homozygous for the age-related macular degeneration risk-conferring variant of complement factor $\mathrm{H}$ have elevated levels of CRP in the choroid. Proc. Natl. Acad. Sci. U.S.A 2006;103:17456-17461. [PubMed: 17079491]

Jun G, Klein BE, Klein R, Fox K, Millard C, Capriotti J, Russo K, Lee KE, Elston RC, Iyengar SK. Genome-wide analyses demonstrate novel loci that predispose to drusen formation. Invest. Ophthalmol. Vis. Sci 2005;46:3081-3088. [PubMed: 16123405]

Kaiser PK. Antivascular endothelial growth factor agents and their development: therapeutic implications in ocular diseases. Am. J. Ophthalmol 2006;142:660-668. [PubMed: 17011860]

Kaiser J. Genetics. First gene for severe dry macular degeneration. Science 2008;321:1146-1147. [PubMed: 18755949]

Kalayoglu MV, Bula D, Arroyo J, Gragoudas ES, D’Amico D, Miller JW. Identification of Chlamydia pneumoniae within human choroidal neovascular membranes secondary to age-related macular degeneration. Graefes Arch. Clin. Exp. Ophthalmol 2005;243:1080-1090. [PubMed: 15909160]

Kanda A, Chen W, Othman M, Branham KE, Brooks M, Khanna R, He S, Lyons R, Abecasis GR, Swaroop A. A variant of mitochondrial protein LOC387715/ARMS2, not HTRA1, is strongly associated with age-related macular degeneration. Proc. Natl. Acad. Sci. U.S.A 2007;104:1622716232. [PubMed: 17884985]

Kaur I, Hussain A, Hussain N, Das T, Pathangay A, Mathai A, Hussain A, Nutheti R, Nirmalan PK, Chakrabarti S. Analysis of CFH, TLR4, and APOE polymorphism in India suggests the Tyr402His variant of $\mathrm{CFH}$ to be a global marker for age-related macular degeneration. Invest. Ophthalmol. Vis. Sci 2006;47:3729-3735. [PubMed: 16936080]

Khabar KS. The AU-rich transcriptome: more than interferons and cytokines, and its role in disease. J. Interferon Cytokine Res 2005;25:1-10. [PubMed: 15684617]

Kindzelskii AL, Elner VM, Elner SG, Yang D, Hughes BA, Petty HR. Toll-like receptor 4 (TLR4) of retinal pigment epithelial cells participates in transmembrane signaling in response to photoreceptor outer segments. J. Gen. Physiol 2004;124:139-149. [PubMed: 15277575]

Klaver CC, Kliffen M, van Duijn CM, Hofman A, Cruts M, Grobbee DE, van Broeckhoven C, de Jong PT. Genetic association of apolipo-protein E with age-related macular degeneration. Am. J. Hum. Genet 1998;63:200-206. [PubMed: 9634502]

Klein R. Overview of progress in the epidemiology of age-related macular degeneration. Ophthalmic Epidemiol 2007;14:184-187. [PubMed: 17896295]

Klein ML, Schultz DW, Edwards A, Matise TC, Rust K, Berselli CB, Trzupek K, Weleber RG, Ott J, Wirtz MK, Acott TS. Age-related macular degeneration. Clinical features in a large family and linkage to chromosome 1q. Arch. Ophthalmol 1998;116:1082-1088. [PubMed: 9715689]

Klein R, Klein BE, Tomany SC, Meuer SM, Huang GH. Ten-year incidence and progression of agerelated maculopathy: The Beaver Dam eye study. Ophthalmology 2002;109:1767-1779. [PubMed: 12359593] 
Klein RJ, Zeiss C, Chew EY, Tsai JY, Sackler RS, Haynes C, Henning AK, SanGiovanni JP, Mane SM, Mayne ST, Bracken MB, Ferris FL, Ott J, Barnstable C, Hoh J. Complement factor H polymorphism in age-related macular degeneration. Science 2005;308:385-389. [PubMed: 15761122]

Klein ML, Francis PJ, Rosner B, Reynolds R, Hamon SC, Schultz DW, Ott J, Seddon JM. CFH and LOC387715/ARMS2 genotypes and treatment with antioxidants and zinc for age-related macular degeneration. Ophthalmology 2008a;115:1019-1025. [PubMed: 18423869]

Klein R, Knudtson MD, Klein BE, Wong TY, Cotch MF, Liu K, Cheng CY, Burke GL, Saad MF, Jacobs DR Jr, Sharrett AR. Inflammation, complement factor H, and age-related macular degeneration. The Multi-Ethnic Study of Atherosclerosis. Ophthalmology 2008b;115:1742-1749. [PubMed: 18538409]

Kliffen M, Sharma HS, Mooy CM, Kerkvliet S, de Jong PT. Increased expression of angiogenic growth factors in age-related maculopathy. Br. J. Ophthalmol 1997;81:154-162. [PubMed: 9059252]

Koch AE, Polverini PJ, Kunkel SL, Harlow LA, DiPietro LA, Elner VM, Elner SG, Strieter RM. Interleukin-8 as a macrophage-derived mediator of angiogenesis. Science 1992;258:1798-1801. [PubMed: 1281554]

Kovacs KA, Pamer Z, Kovacs A, Fekete S, Miseta A, Kovacs B, Kovacs GL. Association of apolipoprotein E polymorphism with age-related macular degeneration and Alzheimer's disease in south-western Hungary. Ideggyogy Sz 2007;60:169-172. [PubMed: 17451062]

Krasnianski A, von Ahsen N, Heinemann U, Meissner B, Kretzschmar HA, Armstrong VW, Zerr I. ApoE distribution and family history in genetic prion diseases in Germany. J. Mol. Neurosci 2008;34:4550. [PubMed: 18157657]

Kuziel WA, Morgan SJ, Dawson TC, Griffin S, Smithies O, Ley K, Maeda N. Severe reduction in leukocyte adhesion and monocyte extravasation in mice deficient in CC chemokine receptor 2. Proc. Natl. Acad. Sci. U.S.A 1997;94:12053-12058. [PubMed: 9342361]

Lafaut BA, Aisenbrey S, Vanden Broecke C, Bartz-Schmidt KU. Clinico-pathological correlation of deep retinal vascular anomalous complex in age related macular degeneration. Br. J. Ophthalmol 2000;84:1269-1274. [PubMed: 11049953]

Laine M, Jarva H, Seitsonen S, Haapasalo K, Lehtinen MJ, Lindeman N, Anderson DH, Johnson PT, Jarvela I, Jokiranta TS, Hageman GS, Immonen I, Meri S. Y402H polymorphism of complement factor $\mathrm{H}$ affects binding affinity to C-reactive protein. J. Immunol 2007;178:3831-3836. [PubMed: 17339482]

Langmann T. Microglia activation in retinal degeneration. J. Leukoc. Biol 2007;81:1345-1351. [PubMed: 17405851]

Launay S, Maubert E, Lebeurrier N, Tennstaedt A, Campioni M, Docagne F, Gabriel C, Dauphinot L, Potier MC, Ehrmann M, Baldi A, Vivien D. HtrA1-dependent proteolysis of TGF-beta controls both neuronal maturation and developmental survival. Cell Death Differ 2008;15:1408-1416. [PubMed: 18551132]

Lee SJ, Kim JH, Kim JH, Chung MJ, Wen Q, Chung H, Kim KW, Yu YS. Human apolipoprotein E2 transgenic mice show lipid accumulation in retinal pigment epithelium and altered expression of VEGF and bFGF in the eyes. J. Microbiol Biotechnol 2007;17:1024-1030. [PubMed: 18050922]

Lehner T. Special regulatory T cell review: The resurgence of the concept of contrasuppression in immunoregulation. Immunology 2008;123:40-44. [PubMed: 18154618]

Lin JM, Wan L, Tsai YY, Lin HJ, Tsai Y, Lee CC, Tsai CH, Tseng SH, Tsai FJ. Vascular endothelial growth factor gene polymorphisms in age-related macular degeneration. Am. J. Ophthalmol 2008;145:1045-1051. [PubMed: 18378209]

Lopez PF, Lambert HM, Grossniklaus HE, Sternberg P Jr. Well-defined subfoveal choroidal neovascular membranes in age-related macular degeneration. Ophthalmology 1993;100:415-422. [PubMed: 7681555]

Lu B, Rutledge BJ, Gu L, Fiorillo J, Lukacs NW, Kunkel SL, North R, Gerard C, Rollins BJ. Abnormalities in monocyte recruitment and cytokine expression in monocyte chemoattractant protein 1-deficient mice. J. Exp. Med 1998;187:601-608. [PubMed: 9463410]

Luo L, Harmon J, Yang X, Chen H, Patel S, Mineau G, Yang Z, Constantine R, Buehler J, Kaminoh Y, Ma X, Wong TY, Zhang M, Zhang K. Familial aggregation of age-related macular degeneration in the Utah population. Vis. Res 2008;48:494-500. [PubMed: 18252239] 
Majewski J, Schultz DW, Weleber RG, Schain MB, Edwards AO, Matise TC, Acott TS, Ott J, Klein ML. Age-related macular degeneration-a genome scan in extended families. Am. J. Hum. Genet 2003;73:540-550. [PubMed: 12900797]

Malek G, Johnson LV, Mace BE, Saloupis P, Schmechel DE, Rickman DW, Toth CA, Sullivan PM, Bowes Rickman C. Apolipoprotein E allele-dependent pathogenesis: a model for age-related retinal degeneration. Proc. Natl. Acad. Sci. U.S.A 2005;102:11900-11905. [PubMed: 16079201]

Mantovani A, Sica A, Sozzani S, Allavena P, Vecchi A, Locati M. The chemokine system in diverse forms of macrophage activation and polarization. Trends Immunol 2004;25:677-686. [PubMed: 15530839]

Mares-Perlman JA, Brady WE, Klein R, VandenLangenberg GM, Klein BE, Palta M. Dietary fat and age-related maculopathy. Arch. Ophthalmol 1995;113:743-748. [PubMed: 7786215]

Mata NL, Tzekov RT, Liu X, Weng J, Birch DG, Travis GH. Delayed dark-adaptation and lipofuscin accumulation in $\mathrm{abcr}^{+-}$mice: implications for involvement of ABCR in age-related macular degeneration. Invest. Ophthalmol. Vis. Sci 2001;42:1685-1690. [PubMed: 11431429]

Midena E, Degli Angeli C, Blarzino MC, Valenti M, Segato T. Macular function impairment in eyes with early age-related macular degeneration. Invest. Ophthalmol. Vis. Sci 1997;38:469-477. [PubMed: 9040480]

Misch EA, Hawn TR. Toll-like receptor polymorphisms and susceptibility to human disease. Clin. Sci. (Lond.) 2008;114:347-360. [PubMed: 18230059]

Mold C, Gewurz H, Du Clos TW. Regulation of complement activation by C-reactive protein. Immunopharmacology 1999;42:23-30. [PubMed: 10408362]

Montes T, Goicoechea de Jorge E, Ramos R, Goma M, Pujol O, Sanchez-Corral P, Rodriguez de Cordoba $\mathrm{S}$. Genetic deficiency of complement factor $\mathrm{H}$ in a patient with age-related macular degeneration and membranoproliferative glomerulonephritis. Mol. Immunol 2008;45:2897-2904. [PubMed: 18336910]

Mori K, Horie-Inoue K, Kohda M, Kawasaki I, Gehlbach PL, Awata T, Yoneya S, Okazaki Y, Inoue S. Association of the HTRA1 gene variant with age-related macular degeneration in the Japanese population. J. Hum. Genet 2007;52:636-641. [PubMed: 17568988]

Mullins RF, Russell SR, Anderson DH, Hageman GS. Drusen associated with aging and age-related macular degeneration contain proteins common to extracellular deposits associated with atherosclerosis, elastosis, amyloidosis, and dense deposit disease. FASEB J 2000;14:835-846. [PubMed: 10783137]

Mullins RF, Aptsiauri N, Hageman GS. Structure and composition of drusen associated with glomerulonephritis: implications for the role of complement activation in drusen biogenesis. Eye 2001;15:390-395. [PubMed: 11450763]

Nordgaard CL, Berg KM, Kapphahn RJ, Reilly C, Feng X, Olsen TW, Ferrington DA. Proteomics of the retinal pigment epithelium reveals altered protein expression at progressive stages of age-related macular degeneration. Invest. Ophthalmol. Vis. Sci 2006;47:815-822. [PubMed: 16505012]

Nordgaard CL, Karunadharma PP, Feng X, Olsen TW, Ferrington DA. Mitochondrial proteomics of the retinal pigment epithelium at progressive stages of age-related macular degeneration. Invest. Ophthalmol. Vis. Sci 2008;49:2848-2855. [PubMed: 18344451]

Nozaki M, Raisler BJ, Sakurai E, Sarma JV, Barnum SR, Lambris JD, Chen Y, Zhang K, Ambati BK, Baffi JZ, Ambati J. Drusen complement components C3a and C5a promote choroidal neovascularization. Proc. Natl. Acad. Sci. U.S.A 2006;103:2328-2333. [PubMed: 16452172]

Nussenblatt RB, Ferris F 3rd. Age-related macular degeneration and the immune response: implications for therapy. Am. J. Ophthalmol 2007;144:618-626. [PubMed: 17698021]

Ogata N, Yamamoto C, Miyashiro M, Yamada H, Matsushima M, Uyama M. Expression of transforming growth factor-beta mRNA in experimental choroidal neovascularization. Curr. Eye Res 1997;16:918. [PubMed: 9043818]

Oka C, Tsujimoto R, Kajikawa M, Koshiba-Takeuchi K, Ina J, Yano M, Tsuchiya A, Ueta Y, Soma A, Kanda H, Matsumoto M, Kawaichi M. HtrA1 serine protease inhibits signaling mediated by Tgfbeta family proteins. Development 2004;131:1041-1053. [PubMed: 14973287]

Okamoto H, Umeda S, Obazawa M, Minami M, Noda T, Mizota A, Honda M, Tanaka M, Koyama R, Takagi I, Sakamoto Y, Saito Y, Miyake Y, Iwata T. Complement factor H polymorphisms in 
Japanese population with age-related macular degeneration. Mol. Vis 2006;12:156-158. [PubMed: 16541016]

Ong JM, Zorapapel NC, Rich KA, Wagstaff RE, Lambert RW, Rosenberg SE, Moghaddas F, Pirouzmanesh A, Aoki AM, Kenney MC. Effects of cholesterol and apolipoprotein E on retinal abnormalities in ApoE-deficient mice. Invest. Ophthalmol. Vis. Sci 2001;42:1891-1900. [PubMed: 11431458]

Patel M, Chan CC. Immunopathological aspects of age-related macular degeneration. Semin. Immunopathol 2008;30:97-110.

Patel N, Ohbayashi M, Nugent AK, Ramchand K, Toda M, Chau KY, Bunce C, Webster A, Bird AC, Ono SJ, Chong V. Circulating anti-retinal antibodies as immune markers in age-related macular degeneration. Immunology 2005;115:422-430. [PubMed: 15946260]

Penfold PL, Wong JG, Gyory J, Billson FA. Effects of triamcinolone acetonide on microglial morphology and quantitative expression of MHC-II in exudative age-related macular degeneration. Clin. Exp. Ophthalmol 2001;29:188-192.

Pickering MC, Cook HT, Warren J, Bygrave AE, Moss J, Walport MJ, Botto M. Uncontrolled C3 activation causes membranoproliferative glomerulonephritis in mice deficient in complement factor H. Nat. Genet 2002;31:424-428. [PubMed: 12091909]

Rakoczy EP, Yu MJ, Nusinowitz S, Chang B, Heckenlively JR. Mouse models of age-related macular degeneration. Exp. Eye Res 2006;82:741-752. [PubMed: 16325179]

Richardson AJ, Islam FM, Guymer RH, Cain M, Baird PN. A tag-single nucleotide polymorphisms approach to the vascular endothelial growth factor-A gene in age-related macular degeneration. Mol. Vis 2007;13:2148-2152. [PubMed: 18079689]

Rinne M, Caldwell D, Kelley MR. Transient adenoviral N-methylpurine DNA glycosylase overexpression imparts chemotherapeutic sensitivity to human breast cancer cells. Mol. Cancer Ther 2004;3:955-967. [PubMed: 15299078]

Rivera A, Fisher SA, Fritsche LG, Keilhauer CN, Lichtner P, Meitinger T, Weber BH. Hypothetical LOC387715 is a second major susceptibility gene for age-related macular degeneration, contributing independently of complement factor $\mathrm{H}$ to disease risk. Hum. Mol. Genet 2005;14:3227-3236. [PubMed: 16174643]

Robman L, Mahdi O, McCarty C, Dimitrov P, Tikellis G, McNeil J, Byrne G, Taylor H, Guymer R. Exposure to Chlamydia pneumoniae infection and progression of age-related macular degeneration. Am. J. Epidemiol 2005;161:1013-1019. [PubMed: 15901621]

Roque RS, Rosales AA, Jingjing L, Agarwal N, Al-Ubaidi MR. Retina-derived microglial cells induce photoreceptor cell death in vitro. Brain Res 1999;836:110-119. [PubMed: 10415410]

Rosenfeld PJ, Brown DM, Heier JS, Boyer DS, Kaiser PK, Chung CY, Kim RY. Ranibizumab for neovascular age-related macular degeneration. N. Engl. J. Med 2006;355:1419-1431. [PubMed: 17021318]

Ross RJ, Bojanowski CM, Wang JJ, Chew EY, Rochtchina E, Ferris FL 3rd, Mitchell P, Chan CC, Tuo J. The LOC387715 polymorphism and age-related macular degeneration: replication in three casecontrol samples. Invest. Ophthalmol. Vis. Sci 2007;48:1128-1132. [PubMed: 17325155]

Ross RJ, Zhou M, Shen D, Fariss RN, Ding X, Bojanowski CM, Tuo J, Chan CC. Immunological protein expression profile in $\mathrm{Ccl} 2 / \mathrm{Cx} 3 \mathrm{cr} 1$ deficient mice with lesions similar to age-related macular degeneration. Exp. Eye Res 2008;86:675-683. [PubMed: 18308304]

Russell SR, Mullins RF, Schneider BL, Hageman GS. Location, substructure, and composition of basal laminar drusen compared with drusen associated with aging and age-related macular degeneration. Am. J. Ophthalmol 2000;129:205-214. [PubMed: 10682974]

Sakurai E, Anand A, Ambati BK, van Rooijen N, Ambati J. Macrophage depletion inhibits experimental choroidal neovascularization. Invest. Ophthalmol. Vis. Sci 2003;44:3578-3585. [PubMed: 12882810]

Sarks SH, Arnold JJ, Killingsworth MC, Sarks JP. Early drusen formation in the normal and aging eye and their relation to age related maculopathy: a clinicopathological study. Br. J. Ophthalmol 1999;83:358-368. [PubMed: 10365048]

Schmidt S, Klaver C, Saunders A, Postel E, De La Paz M, Agarwal A, Small K, Udar N, Ong J, Chalukya M, Nesburn A, Kenney C, Domurath R, Hogan M, Mah T, Conley Y, Ferrell R, Weeks D, de Jong 
PT, van Duijn C, Haines J, Pericak-Vance M, Gorin M. A pooled case-control study of the apolipoprotein E (APOE) gene in age-related maculopathy. Ophthalmic Genet 2002;23:209-223. [PubMed: 12567264]

Schmidt S, Haines JL, Postel EA, Agarwal A, Kwan SY, Gilbert JR, Pericak-Vance MA, Scott WK. Joint effects of smoking history and APOE genotypes in age-related macular degeneration. Mol. Vis 2005;11:941-949. [PubMed: 16288198]

Schmidt S, Hauser MA, Scott WK, Postel EA, Agarwal A, Gallins P, Wong F, Chen YS, Spencer K, Schnetz-Boutaud N, Haines JL, Pericak-Vance MA. Cigarette smoking strongly modifies the association of LOC387715 and age-related macular degeneration. Am. J. Hum. Genet 2006;78:852864. [PubMed: 16642439]

Schultz DW, Klein ML, Humpert A, Majewski J, Schain M, Weleber RG, Ott J, Acott TS. Lack of an association of apolipoprotein $\mathrm{E}$ gene polymorphisms with familial age-related macular degeneration. Arch. Ophthalmol 2003;121:679-683. [PubMed: 12742846]

Seddon JM, Ajani UA, Sperduto RD, Hiller R, Blair N, Burton TC, Farber MD, Gragoudas ES, Haller J, Miller DT, et al. Eye Disease Case-Control Study Group. Dietary carotenoids, vitamins A, C, and E, and advanced age-related macular degeneration. JAMA 1994;272:1413-1420. [PubMed: 7933422]

Seddon JM, Rosner B, Sperduto RD, Yannuzzi L, Haller JA, Blair NP, Willett W. Dietary fat and risk for advanced age-related macular degeneration. Arch. Ophthalmol 2001;119:1191-1199. [PubMed: 11483088]

Seddon JM, Cote J, Rosner B. Progression of age-related macular degeneration: association with dietary fat, transunsaturated fat, nuts, and fish intake. Arch. Ophthalmol 2003;121:1728-1737. [PubMed: 14662593]

Seddon JM, Gensler G, Milton RC, Klein ML, Rifai N. Association between C-reactive protein and agerelated macular degeneration. JAMA 2004;291:704-710. [PubMed: 14871913]

Seddon JM, Francis PJ, George S, Schultz DW, Rosner B, Klein ML. Association of CFH Y402H and LOC387715 A69S with progression of age-related macular degeneration. JAMA 2007;297:17931800. [PubMed: 17456821]

Shanmugaratnam J, Berg E, Kimerer L, Johnson RJ, Amaratunga A, Schreiber BM, Fine RE. Retinal Muller glia secrete apolipoproteins E and J. which are efficiently assembled into lipoprotein particles. Brain Res. Mol. Brain Res 1997;50:113-120. [PubMed: 9406925]

Shen D, Tuo J, Patel M, Herzlich AA, Ding X, Chew EY, Chan CC. Chlamydia pneumoniae infection, complement factor $\mathrm{H}$ variant and age-related macular degeneration (AMD). Br. J. Ophthalmol.2008. 2008 November 7; [Epub ahead of print]

Shuler RK Jr, Schmidt S, Gallins P, Hauser MA, Scott WK, Caldwell J, Agarwal A, Haines JL, PericakVance MA, Postel EA. Peripheral reticular pigmentary change is associated with complement factor H polymorphism (Y402H) in age-related macular degeneration. Ophthalmology 2008;115:520_ 524. [PubMed: 18067970]

Skerka C, Lauer N, Weinberger AA, Keilhauer CN, Suhnel J, Smith R, Schlotzer-Schrehardt U, Fritsche L, Heinen S, Hartmann A, Weber BH, Zipfel PF. Defective complement control of factor H (Y402H) and FHL-1 in age-related macular degeneration. Mol. Immunol 2007;44:3398-3406. [PubMed: 17399790]

Smith C. Genomics: SNPs and human disease. Nature 2005;435:993. [PubMed: 15959523]

Smith W, Mitchell P. Family history and age-related maculopathy: the Blue Mountains Eye Study. Aust. N.Z.J. Ophthalmol 1998;26:203-206. [PubMed: 9717749]

Smith W, Mitchell P, Leeder SR. Dietary fat and fish intake and age-related maculopathy. Arch. Ophthalmol 2000;118:401-404. [PubMed: 10721964]

Smith SR, Tong Z, Constantine R, Brinton E, Cameron J, Gibbs D, Schneider S, Harmon J, Yang Z, Zhang K. Vascular endothelial growth factor (VEGF) polymorphisms and their association with age-related macular degeneration. Invest. Ophthalmol. Vis. Sci 2007:E-2097.

Souied EH, Benlian P, Amouyel P, Feingold J, Lagarde JP, Munnich A, Kaplan J, Coscas G, Soubrane G. The epsilon4 allele of the apolipoprotein E gene as a potential protective factor for exudative age-related macular degeneration. Am. J. Ophthalmol 1998;125:353-359. [PubMed: 9512153] 
Souied EH, Ducroq D, Rozet JM, Gerber S, Perrault I, Munnich A, Coscas G, Soubrane G, Kaplan J. ABCR gene analysis in familial exudative age-related macular degeneration. Invest. Ophthalmol. Vis. Sci 2000;41:244-247. [PubMed: 10634626]

Stone EM, Webster AR, Vandenburgh K, Streb LM, Hockey RR, Lotery AJ, Sheffield VC. Allelic variation in ABCR associated with Stargardt disease but not age-related macular degeneration. Nat. Genet 1998;20:328-329. [PubMed: 9843201]

Tam PO, Ng TK, Liu DT, Chan WM, Chiang SW, Chen LJ, DeWan A, Hoh J, Lam DS, Pang CP. HTRA1 variants in exudative age-related macular degeneration and interactions with smoking and $\mathrm{CFH}$. Invest. Ophthalmol. Vis. Sci 2008;49:2357-2365. [PubMed: 18316707]

Tan JS, Wang JJ, Flood V, Rochtchina E, Smith W, Mitchell P. Dietary antioxidants and the long-term incidence of age-related macular degeneration: the Blue Mountains Eye Study. Ophthalmology 2008;115:334-341. [PubMed: 17664009]

Tsai YY, Lin JM, Wan L, Lin HJ, Tsai Y, Lee CC, Tsai CH, Tsai FJ, Tseng SH. Interleukin gene polymorphisms in age-related macular degeneration. Invest. Ophthalmol. Vis. Sci 2008;49:693698. [PubMed: 18235016]

Tsoumakidou M, Demedts IK, Brusselle GG, Jeffery PK. Dendritic cells in chronic obstructive pulmonary disease: new players in an old game. Am. J. Respir. Crit. Care Med 2008;177:1180-1186. [PubMed: 18337593]

Tsutsumi C, Sonoda KH, Egashira K, Qiao H, Hisatomi T, Nakao S, Ishibashi M, Charo IF, Sakamoto $\mathrm{T}$, Murata T, Ishibashi T. The critical role of ocular-infiltrating macrophages in the development of choroidal neovascularization. J. Leukoc. Biol 2003;74:25-32. [PubMed: 12832439]

Tuo J, Smith BC, Bojanowski CM, Meleth AD, Gery I, Csaky KG, Chew EY, Chan CC. The involvement of sequence variation and expression of CX3CR1 in the pathogenesis of age-related macular degeneration. FASEB J 2004;18:1297-1299. [PubMed: 15208270]

Tuo J, Ning B, Bojanowski CM, Lin ZN, Ross RJ, Reed GF, Shen D, Jiao X, Zhou M, Chew EY, Kadlubar FF, Chan CC. Synergic effect of polymorphisms in ERCC6 5' flanking region and complement factor $\mathrm{H}$ on age-related macular degeneration predisposition. Proc. Natl. Acad. Sci. USA 2006;103:9256-9261. [PubMed: 16754848]

Tuo J, Bojanowski CM, Zhou M, Shen D, Ross RJ, Rosenberg KI, Cameron DJ, Yin C, Kowalak JA, Zhuang Z, Zhang K, Chan CC. Murine ccl2/cx3cr1 deficiency results in retinal lesions mimicking human age-related macular degeneration. Invest. Ophthalmol. Vis. Sci 2007;48:3827-3836. [PubMed: 17652758]

Tuo J, Ross RJ, Reed GF, Yan Q, Wang JJ, Bojanowski CM, Chew EY, Feng X, Olsen TW, Ferris FL III, Mitchell P, Chan CC. The HtrA1 promoter polymorphism, smoking, and age-related macular degeneration in multiple case-control samples. Ophthalmology 2008;115:1891-1898. [PubMed: 18718667]

Tzourio C, Arima H, Harrap S, Anderson C, Godin O, Woodward M, Neal B, Bousser MG, Chalmers J, Cambien F, MacMahon S. APOE genotype, ethnicity, and the risk of cerebral hemorrhage. Neurology 2008;70:1322-1328. [PubMed: 18256366]

Wahl SM. Transforming growth factor-beta: innately bipolar. Curr. Opin. Immunol 2007;19:55-62. [PubMed: 17137775]

Walport MJ. Complement. First of two parts. N. Engl. J. Med 2001a;344:1058-1066. [PubMed: 11287977]

Walport MJ. Complement. Second of two parts. N. Engl. J. Med 2001b;344:1140-1144. [PubMed: 11297706]

Wang JJ, Ross RJ, Tuo J, Burlutsky G, Tan AG, Chan CC, Favaloro EJ, Williams A, Mitchell P. The LOC387715 polymorphism, inflammatory markers, smoking, and age-related macular degeneration. A population-based case-control study. Ophthalmology 2008;115:693-699. [PubMed: 17675241]

Weeks DE, Conley YP, Tsai HJ, Mah TS, Schmidt S, Postel EA, Agarwal A, Haines JL, Pericak-Vance MA, Rosenfeld PJ, Paul TO, Eller AW, Morse LS, Dailey JP, Ferrell RE, Gorin MB. Age-related maculopathy: a genomewide scan with continued evidence of susceptibility loci within the 1q31, 10q26, and 17q25 regions. Am. J. Hum. Genet 2004;75:174-189. [PubMed: 15168325] 
Weng J, Mata NL, Azarian SM, Tzekov RT, Birch DG, Travis GH. Insights into the function of Rim protein in photoreceptors and etiology of Stargardt's disease from the phenotype in abcr knockout mice. Cell 1999;98:13-23. [PubMed: 10412977]

Wong TY, Shankar A, Klein R, Bray MS, Couper DJ, Klein BE, Sharrett AR, Folsom AR. Apolipoprotein E gene and early age-related maculopathy: the Atherosclerosis Risk in Communities Study. Ophthalmology 2006;113:255-259. [PubMed: 16406547]

Wylegala E, Teper SJ. VEGF in age-related macular degeneration. Part II. VEGF inhibitors use in agerelated macular degeneration treatment. Klin. Oczna 2007;109:97-100. [PubMed: 17687925]

Xu H, Chen M, Manivannan A, Lois N, Forrester JV. Age-dependent accumulation of lipofuscin in perivascular and subretinal microglia in experimental mice. Aging Cell 2008;7:58-68. [PubMed: 17988243]

Yang Z, Camp NJ, Sun H, Tong Z, Gibbs D, Cameron DJ, Chen H, Zhao Y, Pearson E, Li X, Chien J, Dewan A, Harmon J, Bernstein PS, Shridhar V, Zabriskie NA, Hoh J, Howes K, Zhang K. A variant of the HTRA1 gene increases susceptibility to age-related macular degeneration. Science 2006;314:992-993. [PubMed: 17053109]

Yang Z, Stratton C, Francis PJ, Kleinman ME, Tan PL, Gibbs D, Tong Z, Chen H, Constantine R, Yang X, Chen Y, Zeng J, Davey L, Ma X, Hau VS, Wang C, Harmon J, Buehler J, Pearson E, Patel S, Kaminoh Y, Watkins S, Luo L, Zabriskie NA, Bernstein PS, Cho W, Schwager A, Hinton DR, Klein ML, Hamon SC, Simmons E, Yu B, Campochiaro B, Sunness JS, Campochiaro P, Jorde L, Parmigiani G, Zack DJ, Katsanis N, Ambati J, Zhang K. Toll-like receptor 3 and geographic atrophy in age-related macular degeneration. N. Engl. J. Med 2008;359:1456-1463. [PubMed: 18753640]

Yannuzzi LA, Negrao S, Iida T, Carvalho C, Rodriguez-Coleman H, Slakter J, Freund KB, Sorenson J, Orlock D, Borodoker N. Retinal angiomatous proliferation in age-related macular degeneration. Retina 2001;21:416-434. [PubMed: 11642370]

Yates JR, Sepp T, Matharu BK, Khan JC, Thurlby DA, Shahid H, Clayton DG, Hayward C, Morgan J, Wright AF, Armbrecht AM, Dhillon B, Deary IJ, Redmond E, Bird AC, Moore AT. Complement C3 variant and the risk of age-related macular degeneration. N. Engl. J. Med 2007;357:553-561. [PubMed: 17634448]

Yu J, Wiita P, Kawaguchi R, Honda J, Jorgensen A, Zhang K, Fischetti VA, Sun H. Biochemical analysis of a common human polymorphism associated with age-related macular degeneration. Biochemistry 2007;46:8451-8461. [PubMed: 17580967]

Zareparsi S, Reddick AC, Branham KE, Moore KB, Jessup L, Thoms S, Smith-Wheelock M, Yashar BM, Swaroop A. Association of apolipoprotein E alleles with susceptibility to age-related macular degeneration in a large cohort from a single center. Invest. Ophthalmol. Vis. Sci 2004;45:13061310. [PubMed: 15111581]

Zareparsi S, Buraczynska M, Branham KE, Shah S, Eng D, Li M, Pawar H, Yashar BM, Moroi SE, Lichter PR, Petty HR, Richards JE, Abecasis GR, Elner VM, Swaroop A. Toll-like receptor 4 variant D299G is associated with susceptibility to age-related macular degeneration. Hum. Mol. Genet 2005;14:1449-1455. [PubMed: 15829498] 

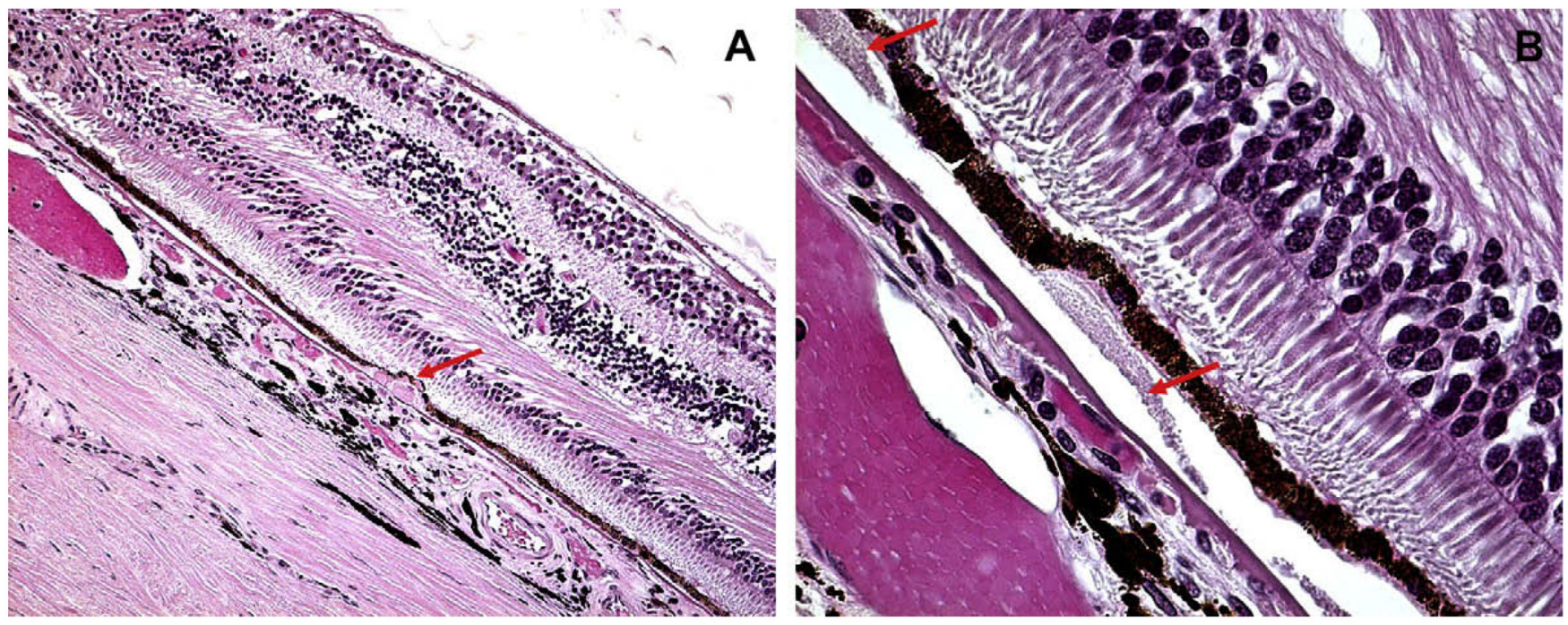

Fig. 1.

Hard and soft drusen. (A) Hard drusen, a small, discrete, punctate druse (arrow) with hyalinelike material located beneath the basal cell surface of the RPE and in Bruch's membrane. (B) Soft drusen, large dome-shaped, hyaline granular deposits with poorly demarcated boundaries (arrow) beneath the RPE. Bruch's membrane is thickened. 


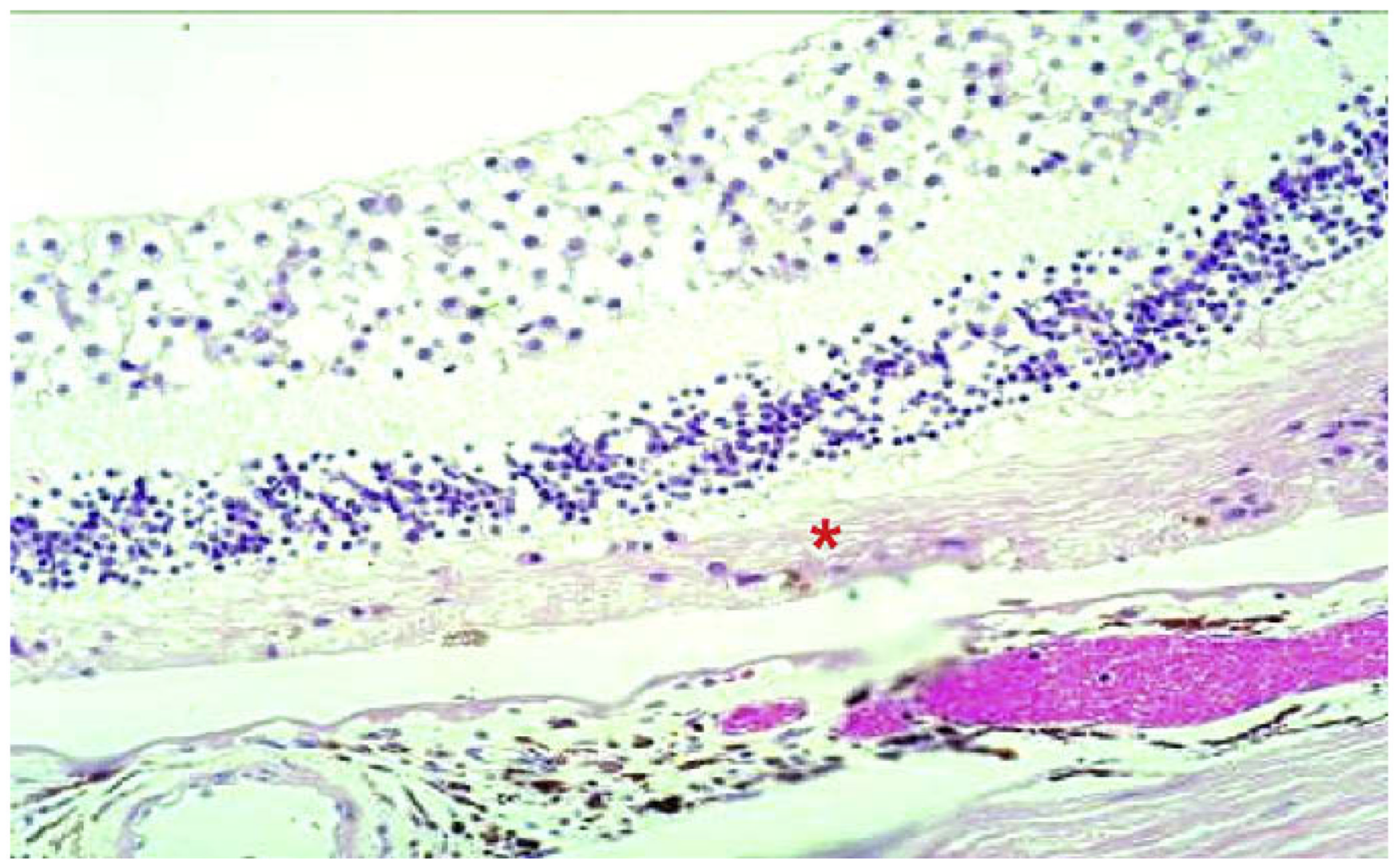

Fig. 2.

Geographic atrophy in AMD. There is degeneration of RPE cells and most of the photoreceptors (asterisk). 


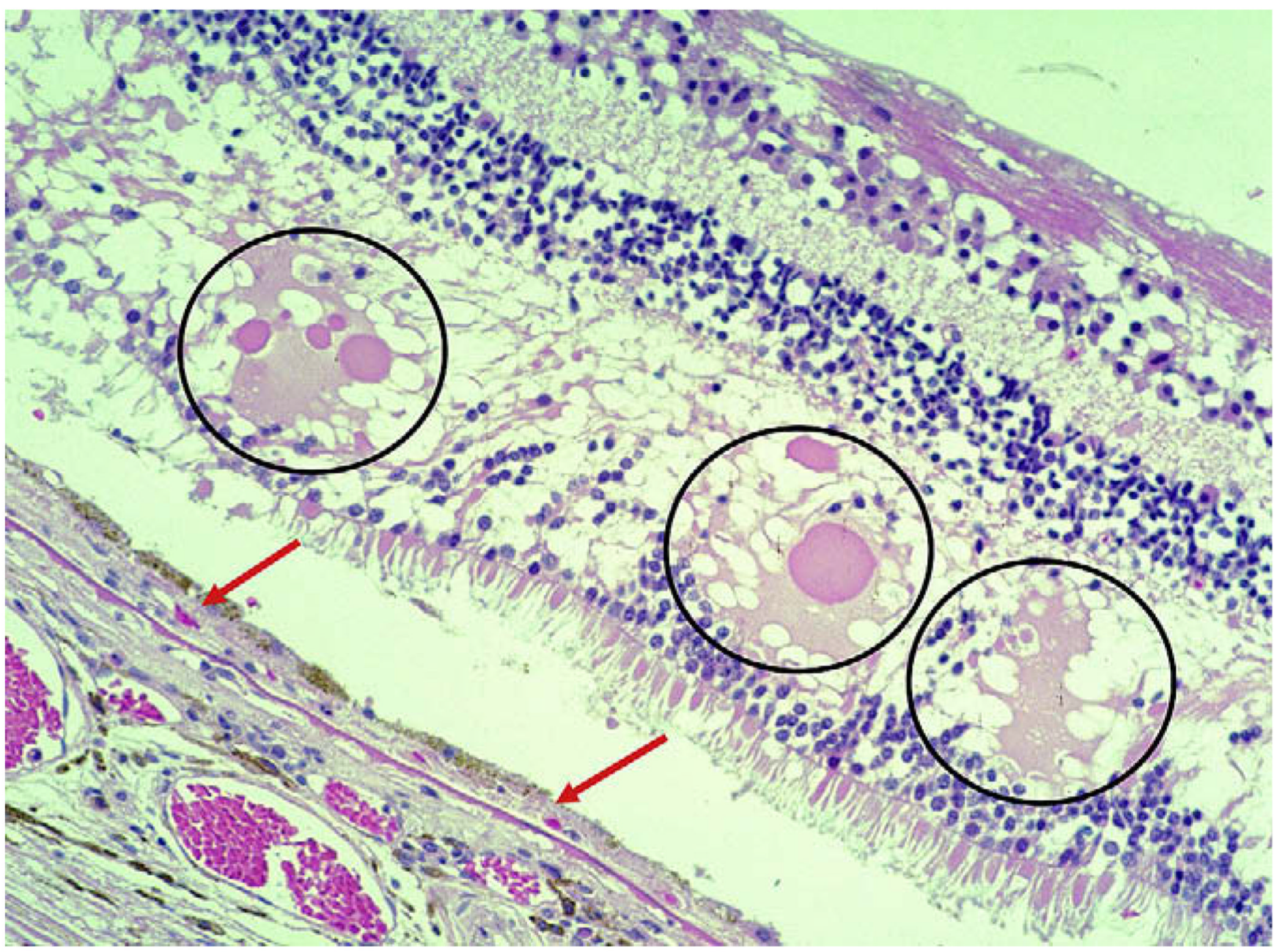

Fig. 3.

Neovascular AMD. There is a thin layer of fibrovascular membrane (CNV) between the RPE and Bruch's membrane (arrows). Serous fluid (circles) due to leakage from neovascular membranes is seen in the outer plexiform layer of the retina. 
A

SNP T280M]

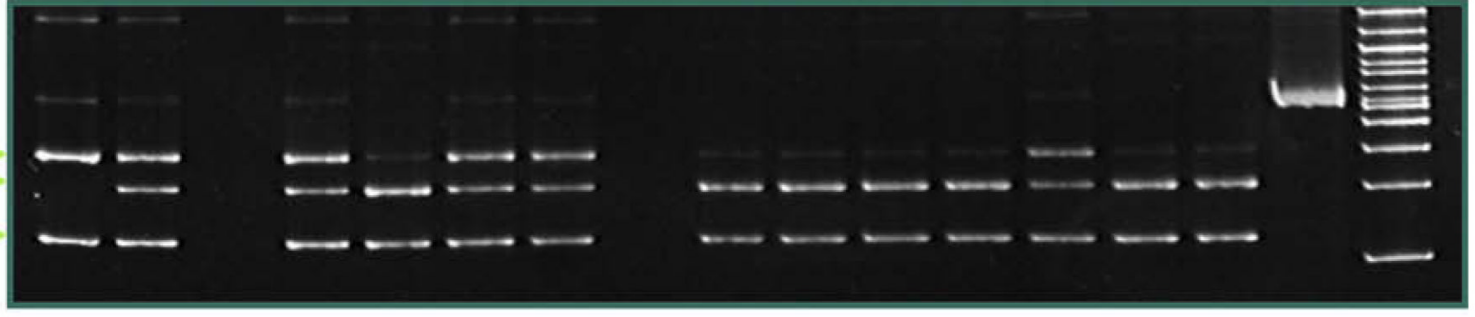

12

34

B

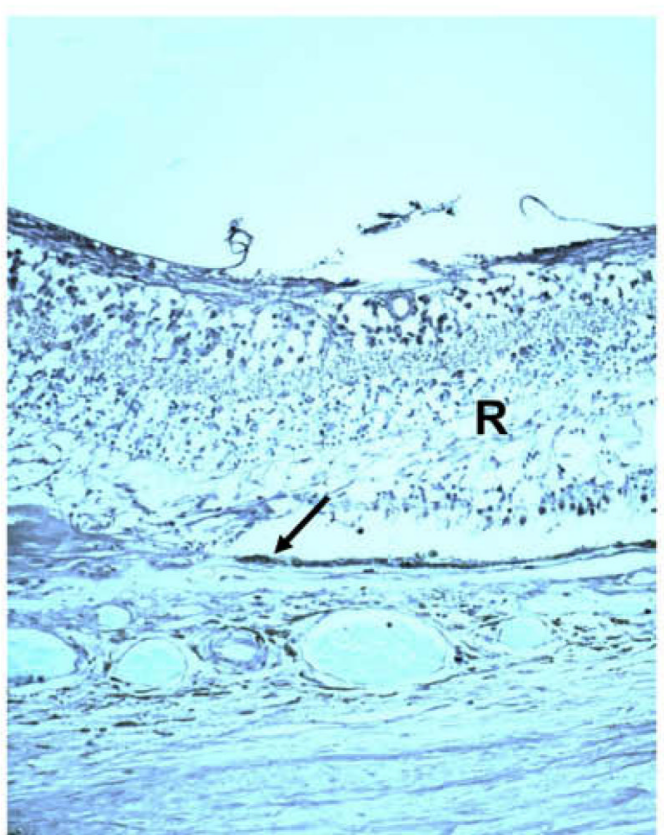

Fig. 4.

CX3CR1 in AMD eyes. (A) Different CX3CRI SNP patterns are detected in AMD cases. Lane 1 demonstrates two bands $(372,216 \mathrm{bp})$, indicating homozygosity for the risk-conferring CX3CR1 T280M SNP. Lanes 2 and 3 reveal three bands (372, 297, $216 \mathrm{bp}$ ), representing heterozygous cases. Lane 4 demonstrates a wild-type (normal) case, which is indicated by two bands (297, 216 bp). (B) Low CX3CR1 expression (arrow) is observed in an AMD eye with CX3CR1 T280M. 

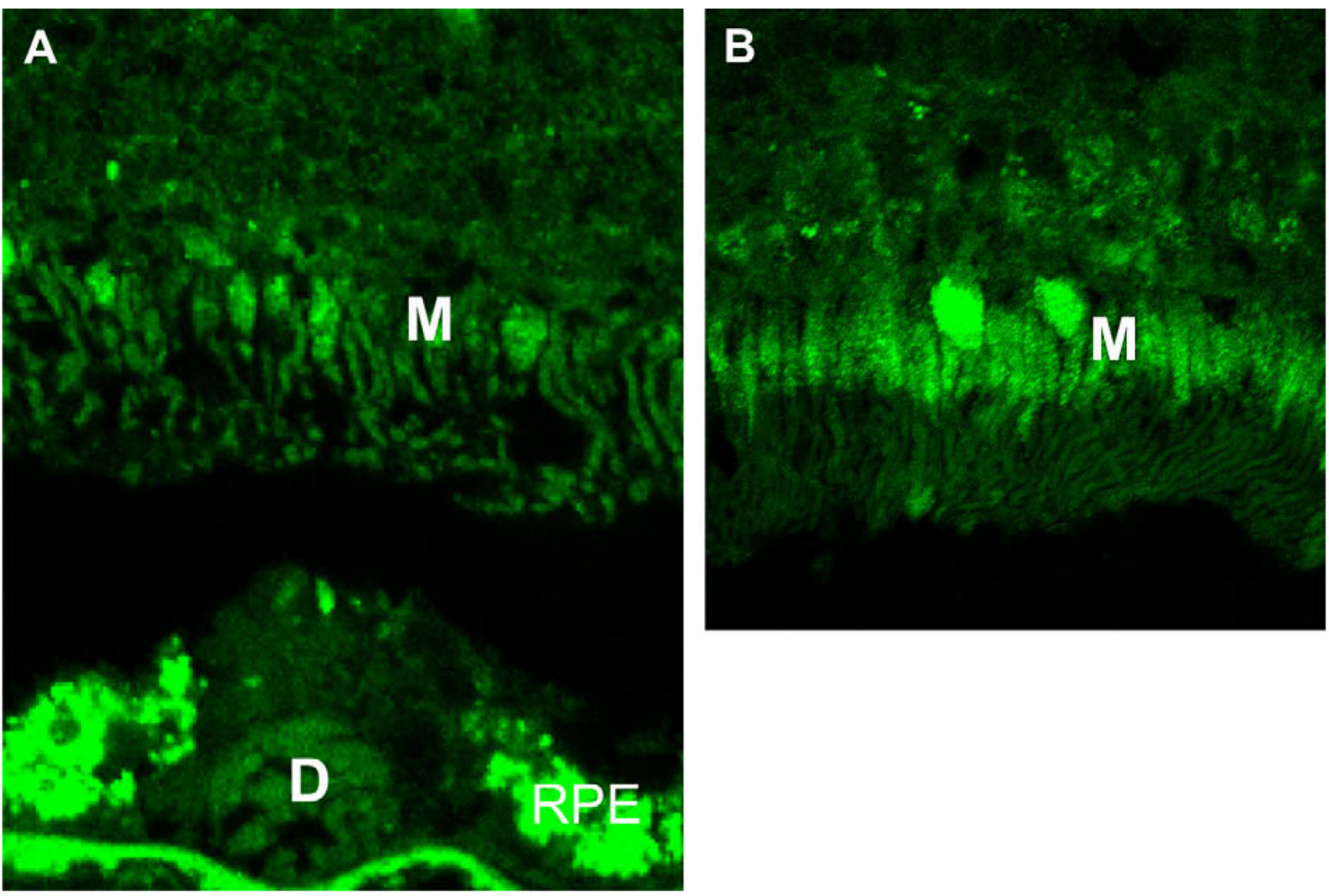

Fig. 5.

Decreased mitochondria in AMD retina. The number of mitochondria $(\mathrm{M})$ is much lower in the inner segment of photoreceptors of the AMD eye (A) as compared with a normal agecontrol eye (B). Accumulation of lipofuscin is known to autofluoresce (in yellowish green color) in the RPE and drusen of the AMD eye (green: immunofluorescence staining with antihuman COV IV, a specific marker of mitochondria). 


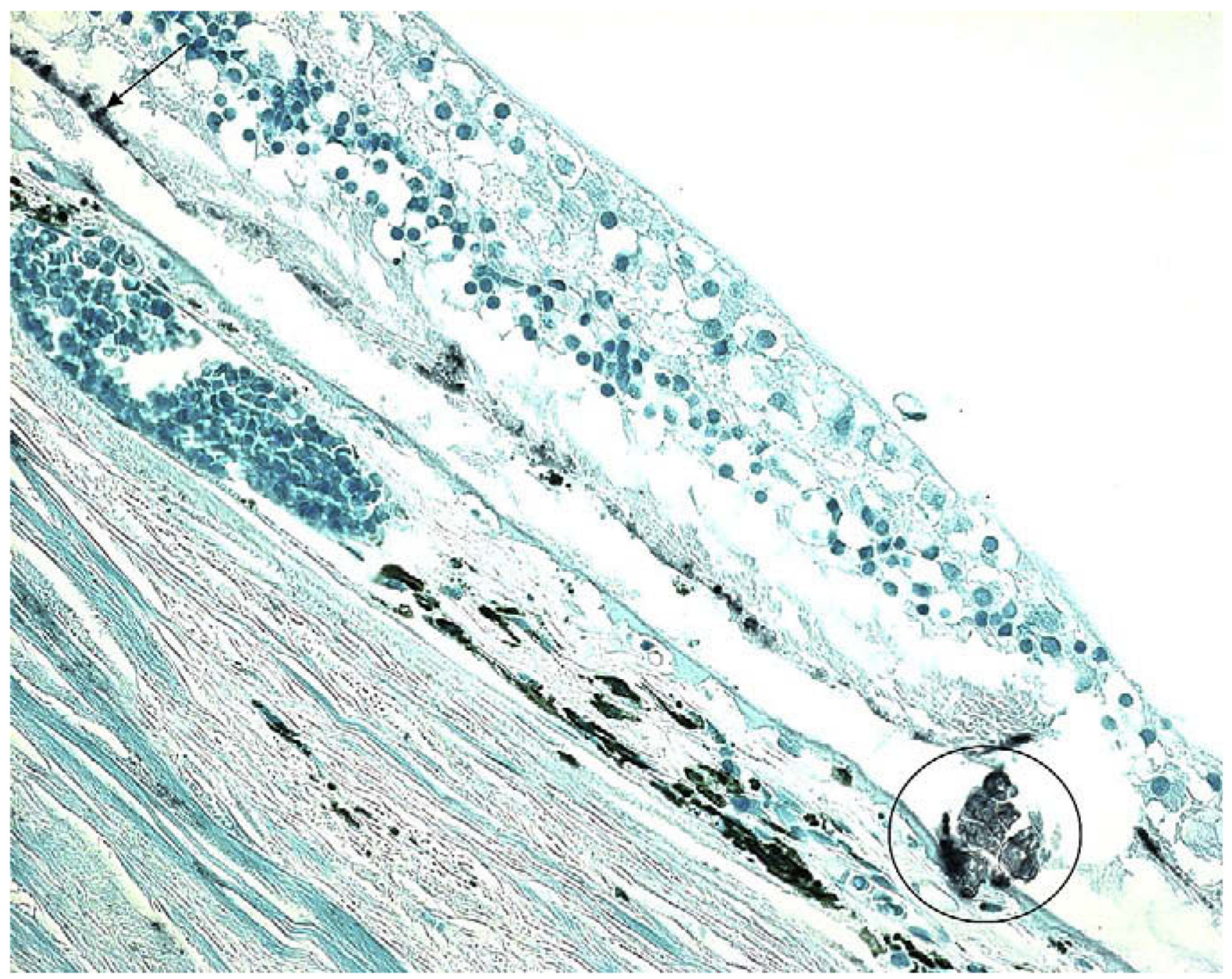

Fig. 6.

HtrA1 expression in AMD eye. Positive immunoreactivity for HtrA1 is observed in the AMD lesion (circle) and residual RPE cells (arrow). 